\title{
Orientation as a strategy of spatial reference ${ }^{\star}$
}

\author{
Angela Terrill and Niclas Burenhult \\ Radboud University Nijmegen / Max Planck Institute for Psycholinguistics
}

\begin{abstract}
This paper explores a strategy of spatial expression which utilizes orientation, a way of describing the spatial relationship of entities by means of reference to their facets. We present detailed data and analysis from two languages, Jahai (Mon-Khmer, Malay Peninsula) and Lavukaleve (Papuan isolate, Solomon Islands), and supporting data from five more languages, to show that the orientation strategy is a major organizing principle in these languages. This strategy has not previously been recognized in the literature as a unitary phenomenon, and the languages which employ it present particular challenges to existing typologies of spatial frames of reference.
\end{abstract}

\section{Introduction}

\subsection{Background}

This work arises out of the framework of the linguistic analysis of frames of reference, as developed by Pederson et al. (1998), Senft (2001), Levinson (1996, 2003) and others. The data to be reported stems from the results of an elicitation task, 'Man and Tree' (described in detail below), developed at the Max Planck Institute for Psycholinguistics. This task is specifically designed to elicit strategies of spatial description of static location in small-scale space and to reveal which frames of reference languages use for such description.

Frames of reference are coordinate systems for expressing a spatial relationship between Figure and Ground. Levinson 1996 and 2003 represent the major current works of reference on spatial frames of reference in the linguistic literature. For Levinson, there are three (and only three) frames of reference, defined loosely as follows. The 'intrinsic' frame of reference expresses the spatial relationship between Figure and Ground on the basis of inherent features (or 'facets', see \$1.3.4) of at least one of them. Typical examples of inherent features are fronts, sides and backs: thus an example of the use of the intrinsic frame of reference is The pen is at the front of the computer. In this example, the computer has an inherent front and 
back, and the pen is located with respect to one of these inherent features, namely the front. In the 'relative' frame of reference Figure and Ground are related to each other by means of a viewpoint external to the Figure-Ground configuration. For example, an English speaker would interpret The pen is left of the computer as meaning, from the point of view of the speaker, that the pen can be found to the left of the computer. In the 'absolute' frame of reference, Figure and Ground are related to each other by means of an abstract bearing, in such a way that by following the bearing from the Ground, one may arrive at the Figure. Thus for example, in The institute is south of the city, one is able to locate the institute by mentally drawing a line from the city following the bearing of 'south'.

This framework of linguistic analysis has been developed partly as a demonstration of the fact that languages vary in something as fundamental as this element of spatial conceptualization, and thus that categories of spatial cognition are not universal. The research has shown that there is striking cross-linguistic variation in which frames of reference are used to describe configurations (henceforth also 'arrays') of objects in small-scale space.

Pederson et al. (1998) present a typology of languages based on their types of frame of reference. Their study is concerned primarily with transverse (i.e. lateral) spatial relations; that is, in the 'Man and Tree' task they are interested in propositions that distinguish between pictures in which a man is on one side of a tree, versus pictures in which the man is on the other side of the tree. In their sample of thirteen languages, only two, Mopan and Kilivila, do not distinguish between these transverse configurations. In the languages which do distinguish these pictures, descriptions make use of conventional spatial information which is independent of the configuration beyond the information just about features of the Figure and Ground. Such conventions may take the form of viewpoints, and descriptions are then classified as representing a relative frame of reference (e.g. man standing to left of tree). Languages relying heavily on this strategy include Japanese and Dutch. If the conventions involve abstract bearings, the descriptions are classified as absolute (e.g. man stands east of tree). Languages primarily employing this strategy include Arandic, Tzeltal and Longgu.

In Mopan and Kilivila, however, descriptions place the tree with respect to inherent features of the man, that is, they employ array-internal information. The authors point out that languages like these will find it hard to distinguish between scenes which are constant in the tree's placement with respect to inherent features of the man but which differ in the transverse location of the man and the tree. The two languages were characterized in terms of not making such spatial distinctions, and of their lack of spatial categorization possibilities that are available in other languages (Pederson et al. 1998: 568-570). Pederson et al. (1998) focus their attention on the languages that $d o$ distinguish between such arrays. 
More detailed accounts of the Mopan and Kilivila data can be found in Danziger 1997 and 1999, and Senft 2001, respectively. For other detailed accounts stemming from the same framework of elicitation and analysis, see Levinson and Wilkins, in press, which contains a collection of articles describing spatial language in a number of genetically and geographically diverse languages. For further work on spatial reference in Mopan, see Danziger 1994, 1996, 2004.

The purpose of this paper is to investigate further two languages with similar properties which seem particularly difficult to analyze in the current typological framework of spatial frames of reference, Jahai (Mon-Khmer, Malay Peninsula) and Lavukaleve (Papuan isolate, Solomon Islands), with the aim of showing these languages from a different perspective. We do so on the basis of new 'Man and Tree' data. We argue that such languages are extremely consistent in their employment of spatial reference strategies. But the consistency lies in a rather different area: these languages use a specific strategy which we will call orientation, which presents a powerful and flexible alternative approach to spatial expression. In fact, such languages provide a particularly interesting opportunity to understand what drives and motivates the choice of spatial expression in a particular language. We also argue that these languages are by no means peculiar in their systematic exploitation of orientation as a means of spatial expression. In fact, many languages seem to make consistent use of this strategy.

Our argument is that orientation rather than a particular frame of reference is conventionalized as the major strategy of spatial reference in some languages. However, we wish to make clear at the outset that this is not to say that frames of reference are irrelevant in such languages but rather, as we will show, that they are difficult to apply analytically and certainly do not emerge naturally from the data.

\subsection{The 'Man and Tree' task}

The data presented in this paper come from a so-called 'Director-Matcher' elicitation task from a family of tasks subsumed under the heading 'Man and Tree' (CARG 1992). Pederson et al. 1998 and most subsequent linguistic work on frames of reference have been based on this family of tasks. The particular version used here is a more recent version developed by Ann Senghas in 1999. All are elicitation tasks designed to reveal strategies of spatial description of static location in small-scale space. The 'Ann Senghas task' consists of two identical sets of sixteen color photographs, each one involving a static array of two objects: a small plastic man, and a small plastic tree (Figure 1). The set of photos includes the man and tree arranged in sixteen spatial configurations with respect to each other on the horizontal plane. One item (the tree) is included as an object which has no intrinsic facets, whereas the other (the man) has salient intrinsic facets. 


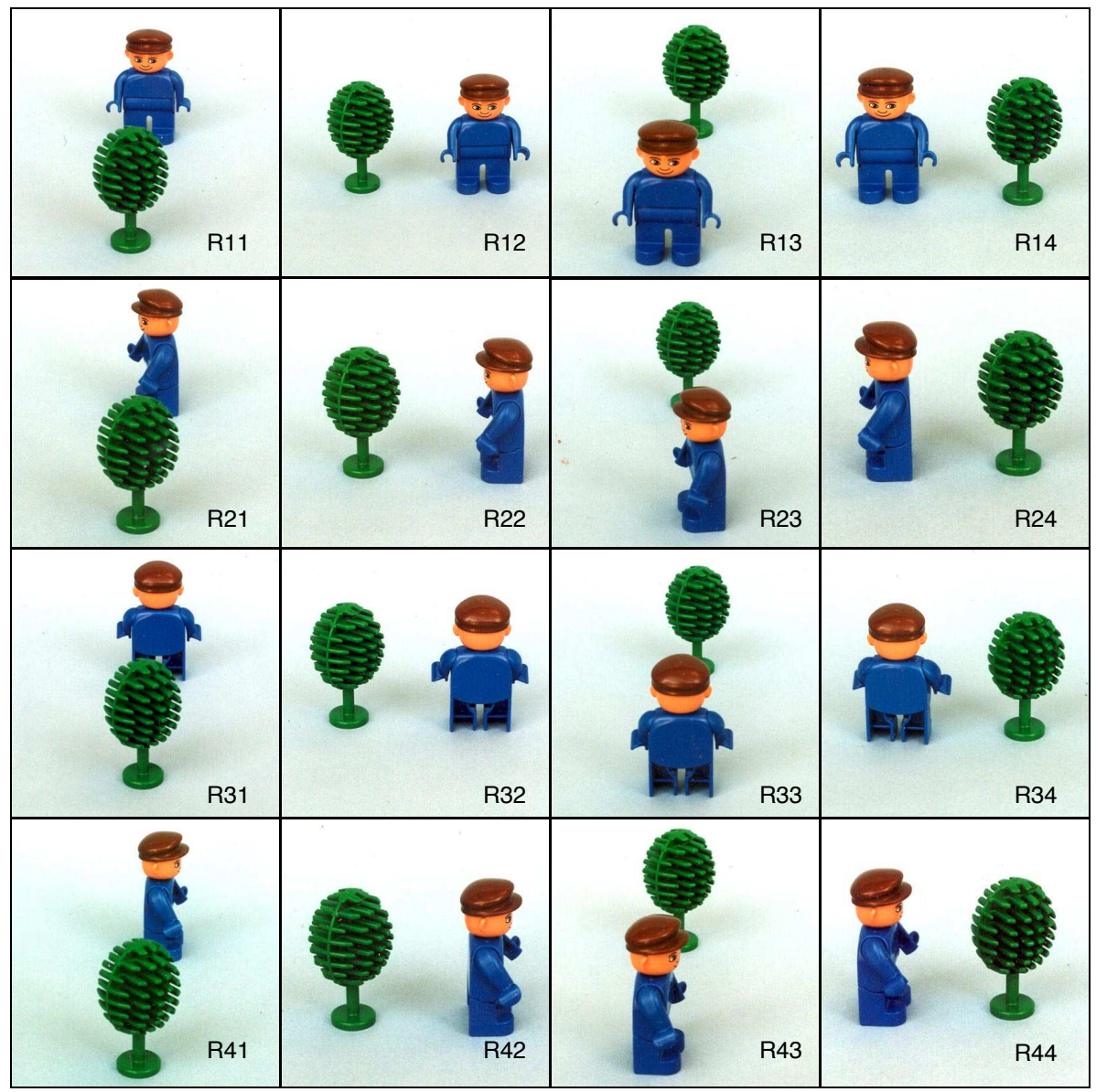

Figure 1. 'Man and Tree' stimulus set (Ann Senghas version).

One consultant (the director) is given one set of photos, from which he or she selects one photo and describes the scene shown in that photo in such a way as to enable the other consultant (the matcher) to identify the correct photo from an identical set. The matcher cannot see the photo which the director is describing. The matcher is free to ask questions. If an incorrect picture is chosen, the matcher tries again until the correct picture is identified. ${ }^{1}$ To solve the task the director must provide information specifying which of the four different positions on the transverse plane the man is in with respect to the tree, and for each position which of the four possible ways the man is facing. The 'Ann Senghas task' differs from other 'Man and Tree' tasks in that it contains no distracter pictures, and in that it includes all possible combinations of the four positions of the man with respect to the tree, with the four ways in which the man is facing. Thus it provides a more exhaustive stimulus set than previous versions of 'Man and Tree' for transverse 
spatial arrays on the horizontal plane. We also use data (in the Lavukaleve description) from one other 'Man and Tree' task known as 'Game 2'. This task involves photos whose distinctions are identical to some of those in the 'Ann Senghas task', with some extra distracter pictures. Included in the current analysis are only those photos which are spatially equivalent to photos in the Senghas set. See Pederson et al. 1998, Danziger 1999, Senft 2001 and Levinson \& Wilkins 2006, for further description of the family of earlier 'Man and Tree' tasks.

To enable cross-linguistic comparison, we limit our discussion to data obtained from comparable tasks, and therefore we discuss only data obtained from the 'Man and Tree' task. Although the data used in this study is thus limited, the results obtained are consistent with natural spatial description found in both languages for static spatial configurations in small-scale space.

\subsection{Terminology used in this paper}

At the outset it is important to clarify our use of some terms.

\subsubsection{Distinguishing propositions}

In analyzing the data, we have focused on propositions which allow the matcher of the game to narrow the search among the pictures available. That is, we concentrate on information which is relevant in solving the task, namely that relating to location and orientation (see \$1.3.5). Propositions containing such disambiguating information are referred to by Pederson et al. (1998: 566) as 'distinguishing propositions. The data also contains information which is not pertinent to the analysis, such as reference to the color of the man's clothes or whether he is sitting or standing, which we have ignored.

\subsubsection{Figure and Ground}

Most work discussing spatial characteristics of arrays distinguishes between Figure and Ground (Talmy 1983: 232). This terminology is also employed here, although sparingly. This is because, for us, the difference between the two is one of discourse salience which has no relevance to their spatial relationship or how their spatial relationship is determined. For instance, in describing intrinsic relationships, we consider both Figure and Ground to have the ability to be assigned asymmetries in the form of inherent features or 'facets' (see \$1.3.4). Here we conform to the definition of Levinson et al. (2002: 173), who state that "for intrinsic coding either the ground (or landmark) object or the figure (object to be located) must have intrinsic features". This definition is in contrast with that of some other previous work, including that of Palmer (2002a: 109-110), for example, in which it is only the Ground (or Relatum) which is assigned asymmetries in an intrinsic relation- 
ship. Therefore, the identification of entities as Figure or Ground is not crucial to our account of intrinsic relationships; such relationships are considered to exist as soon as two entities are spatially related to each other by means of asymmetries of one (or, more rarely, both) of them.

\subsubsection{Cues}

We use the term 'cue' as a generic label for any category, or reference to any entity, which is spatially relevant for the creation of distinguishing propositions in solving the task. Thus, references to the entities of the 'Man and Tree' array as well as to their inherent asymmetries are 'cues', as are all picture-external strategies employed, including e.g. viewpoints, first person, demonstratives, landmarks, place names, and cardinal directions.

\subsubsection{Facets}

A class of cues which is central to our discussion denotes asymmetries of objects, that is, more or less inherent features of objects which can be used in describing spatial relationships. Here, the preferred term for such features will be 'facets'. In the 'Man and Tree' context, descriptively relevant facets typically include asymmetries of the man. These may be signaled explicitly, e.g. with body-part terms (face, chest, back, etc.) or relational expressions (front, behind, right, left, etc.). Facets can also be indicated implicitly, e.g. in expressions like He is turned... and He is looking...

\subsubsection{Location vs. orientation}

In previous analyses of 'Man and Tree' data, distinguishing propositions are classified as representing either 'standing information' or 'facing information' (see e.g. Pederson et al. 1998: 567, Senft 2001: 536 and Levinson \& Wilkins 2006). As far as we can determine, these categories are syntactically based in that it is the standing vs. facing of the grammatical subject of the proposition that decides which category the proposition belongs to. Thus, The man is to the east and The tree is in front of the man are examples of 'standing information', whereas The man is facing east and The man is looking at the tree represent 'facing information'.

However, for our purposes we have found it more convenient to make a different distinction, namely that between 'location' and 'orientation.' 'Location' involves distinguishing propositions describing the locational relationship between the two entities of the 'Man and Tree' array on the horizontal axes (sagittal and lateral to the players) by employing cues which exist independently of the array, e.g. The man is east of the tree and The man is left of the tree. In other words, a locational proposition describes in which of the four possible positions in relation to the tree the man is placed. 
'Orientation' involves distinguishing propositions which rely on facets of an entity in the 'Man and Tree' array to describe its spatial relation to a cue. This cue can either be part of the 'Man and Tree' array itself, as in The tree is at the man's back or The man is facing the tree, or independent of it, as in The man is facing east or The man is facing left. In other words, an orientational proposition provides information as to how the man is oriented in relation to something, but it provides no information as to which of the four possible positions he is placed in with respect to the tree. We use the term 'orientation' for the sake of simplicity but acknowledge that it may not be semantically optimal; note also that the term has been used informally in some previous 'Man and Tree' analyses to refer to 'facing information' (see e.g. Levinson 2006). Here, however, an orientational description is considered to exist as soon as a spatial relationship relies on the spatial coordination of the faceted entity with a cue. Indeed, 'faceted spatial coordination' may be a more pertinent (although far too cumbersome) label for this type of spatial description. ${ }^{2}$

In relation to conventional frames-of-reference analysis, note that, under the definition of 'orientation' employed here, intrinsic descriptions (which by definition draw on inherent facets in relating two objects to each other) will always be orientational (e.g. The tree is in front of the man and The man is facing the tree). However, orientational descriptions are, again in relation to conventional framesof-reference analysis, not necessarily intrinsic (e.g. The man is facing east and The man is facing left). A 'locational' description, on the other hand, can be absolute or relative, but never intrinsic.

Note also that our categorization differs from that of previous accounts in that we abstract away from syntactic expression. Therefore, propositions describing the tree's relation to the facets of the man (e.g. The tree is at the man's back) are treated as orientational just like descriptions in which a facet of the man is related to the tree (e.g. The man's back is towards the tree). Although differing in syntax and information structure, the two describe exactly the same spatial configuration based on the man's facets, and accordingly we treat them as equivalent.

More specifically, the difference between the two is a matter of which element of the spatial array the speaker chooses to highlight as the spatially more stable entity with which the other, more unstable entity is coordinated. In a proposition like The man's back is towards the tree, the focus is on coordinating a facet of the man with the tree. Figuratively, the man can be thought of here as unstable, potentially rotating on his own axis and having the possibility to be coordinated with the tree by means of several competing facets. In a proposition like The tree is at the man's back, the focus is on coordinating the tree with a facet of the man. Figuratively, it is now the tree which can be thought of as unstable, potentially orbiting around the man and thus having the possibility to be coordinated with the man by means 
of his several competing facets. The two proposition types can easily be seen as reflecting a flexible Figure/Ground relationship, where the stable entity always represents the Ground to which an unstable Figure is related. Thus, the difference lies in how the Figure/Ground relationship is mapped onto the entities, particularly whether Ground-status is assigned to the faceted or the non-faceted entity. But, to reiterate, the two propositions describe the same spatial array, and they therefore differ only in the way the speaker chooses to structure the information about the orientational coordination of the two entities.

As far as we are aware, this particular point has never been addressed in the frames-of-reference literature, but it is critical in the analysis we put forward in this paper. We motivate this merging of proposition types with the fact that we are unable to identify a principled way to separate them semantically in our data, and are unable to think of a principled way in which this could be done cross-linguistically. In addition, we see no reason to separate these proposition types given the fact that within the stimuli set both proposition types will always pick out the same subset of pictures. That is, we consider them to be functionally equivalent, and formally to differ only in information structure.

As a further point, note that in the $4 \times 4$ matrix of pictures given in Figure 1, 'locational' information distinguishes pictures horizontally. For example, pictures R11, R12, R13 and R14 show the man in four different locations with respect to the tree, whereas pictures R11, R21, R31 and R41 show him in the same location. 'Orientational' information, on the other hand, distinguishes pictures both horizontally and vertically. Horizontally, pictures show the man with different orientation in relation to the tree but with the same orientation in relation to the wider world (e.g. the viewer), as in R11, R12, R13 and R14. Vertically, pictures show the man with different orientation in relation to both the tree and the wider world, as in R11, R21, R31 and R41. 'Orientational' information therefore has the potential to disambiguate all pictures of the set, whereas 'locational' information can disambiguate only a subset of pictures.

\subsection{Structure of this paper}

Sections 2 and 3 describe in detail the results of the 'Man and Tree' task from Jahai and Lavukaleve, respectively; as such, they form the main body of the paper. Section 4 discusses problems arising from this data in trying to assign frames of reference, and introduces the idea of orientation as the organizing principle of these two languages. Section 5 introduces data from five more languages - Kilivila, Mopan, Jaminjung, Yélî Dnye and Semnam - to support the idea that orientation is not just an unusual aberration in two languages but rather a strategy common to these seven languages for which 'Man and Tree' data is currently available, and 
probably many others. Section 6 summarizes our findings and concludes with a brief discussion of the relationship between orientation as an organizing principle for spatial reference and frames of reference themselves.

\section{Jahai 'Man and Tree' data}

2.1 Introduction to the language and its speakers

Jahai is a Mon-Khmer language spoken by about 1,000 hunter-gatherers, traders and occasional slash-and-burn cultivators in the Malay Peninsula. The Jahai speakers form the largest ethnic group of a cluster of peninsular hunter-gatherer populations referred to generically as Semang. Their subsistence system is based on hunting, fishing and the collecting of wild tubers and vegetables. Traditionally, the Jahai live in mobile bands of 15-50 people, sheltering in windbreak huts and moving camp every one to two weeks. Nowadays many Jahai lead a settled or semi-settled life in regroupment villages established by the Malaysian government (van der Sluys 1999: 308-310, Burenhult 2005a: 1-2).

The Jahai territory covers a landlocked area of about 3,500 square kilometers in northern Peninsular Malaysia and adjacent parts of southern Thailand. Its topography is dominated by the mountains of the Titiwangsa range, and the relief ranges between about 100 and 1,800 meters above sea level. The area forms a maze of narrow, steep-sided valleys and is drained by swift-flowing mountain streams, which are fed by countless rivulets that trickle down from their sources on the mountainsides. Drainage occurs in two major directions: the main, western part of the territory is drained by the upper reaches of the Perak, which flows southwest to the Straits of Malacca; a smaller, eastern part is drained by the Pergau, which flows southeast towards the Kelantan, which meets the South China Sea near Kota Bharu. The vegetation is made up of mostly primary Dipterocarp rainforest characteristic of foothills and lower mountain regions, which forms a dense cover over most of the mountainous territory. Rainfall averages $2,250 \mathrm{~mm}$ per year and occurs year-round.

The Jahai language is a member of the Northern Aslian subgroup of the Aslian languages, a branch of Mon-Khmer spoken exclusively in the Malay Peninsula. Characteristic features include a rich system of vowel phonemes, a complex system of word formation involving intricate processes of derivational affixation and reduplication, and rich pronominal and demonstrative distinctions. The language is heavily influenced by Malay, the Austronesian majority language of the peninsula, as reflected for example in a large number of loanwords (Burenhult 2005a). 


\subsection{Spatial reference in Jahai}

In Jahai, everyday spatial reference involves a number of linguistic strategies. These include, for example, the rich eight-term system of demonstratives, which encodes a range of parameters related to accessibility and spatial location of the referent, as well as the addressee's cognitive (e.g. attentional) relation to the referent (Burenhult 2003, forthc. a, b). Another important strategy is the use of inherent facets of objects in describing spatial relationships. Mapping of such facets onto entities typically involves the metaphorical extension of body-part terms; the body metaphor forms a very systematic, coherent and productive template with which the rest of the physical world is mapped (Burenhult 2005b, 2006). Such reference also employs a set of relational nouns which are combined with other nouns in compound-like constructions. Such relational nouns include 'upper side', 'lower side, 'front side,' 'back side', 'inside', etc. A less understood dichotomy of 'inside' vs. 'outside' represents yet another type of spatial description. This distinguishes the 'interior' concept $k l \varepsilon \eta$ 'inside', associated with 'hut' and 'camp', from the 'exterior' concept of $h$ ip 'forest', 'outside' (Burenhult 2005b). An inside/outside distinction is also apparent in parts of the demonstrative system, in this case associated with the layout of the speech situation (Burenhult, forthc. b).

Larger-scale directional reference is predominantly associated with river profile. This involves an upstream/downstream distinction which is reflected linguistically in the metaphorical landscape terms kuy tom 'headwaters' (literally 'water-head') and kit tom 'river mouth' (literally 'water-bum'), in the relational nouns krpin 'upper side' and kymm 'lower side', as well as in the elevation-encoding demonstrative distinctions 'itith 'there up' and 'uyih 'there down'. Used for both short-distance local reference and more distant geographical reference, these directions are dependent on the actual profile and are not abstracted away from the direction of the flow of water; the referential direction changes with individual rivers, streams and even bends. Thus, there is no abstract system of fixed bearings based on river profile.

In Jahai myth-telling, large-scale spatial reference sometimes involves a system of bearings based on the East-West axis. The axis is conceptualized as a body arching face down across the sky, the main directions being referred to as tom $k t \jmath^{\text {? }}$ 'East' (literally 'sky-base') and sen kto? 'West' (literally 'sky-front'). This system of directions is not used in everyday spatial reference.

It is noteworthy that the Jahai do not employ an abstract system of bearings for everyday spatial description. This sets them apart from other hunter-gatherer groups whose spatial systems have been investigated, including e.g. the Guugu Yimithirr of Northern Queensland (Levinson 1997, 2003: 113-146, Haviland 1998), the Arrernte of Central Australia (Pederson et al. 1998, Levinson 2003: 170-215), 
the Hai//om of the Kalahari (Widlok 1997) and various Eskimo groups (Fortescue 1988). The Jahai thus provide an exception to Levinson's proposed association of the hunting-gathering lifestyle with such systems (Levinson 2003: 212).

\subsection{Set-up of the task}

The Jahai 'Man and Tree' data presented here was collected in 2002 by Niclas Burenhult among the semi-settled Jahai inhabitants of Sungai Banun, a regroupment village in Hulu Perak district, in the state of Perak, Peninsular Malaysia. It consists of four sessions of the 'Ann Senghas task'; three of these were run in the village and one was run in the forest, a few hundred meters upstream from the village along the Banun River (referred to by the Jahai as Cos). One of the village sessions was conducted indoors; the other village sessions as well as the forest session were conducted outdoors. The two outdoor village sessions took place in the same location but with different orientations (180-degree rotation). The sessions were run on separate occasions, with several days in between. Altogether six male Jahai consultants, aged between about 25 and 70, took part in the task. One consultant was director of two sessions and another consultant was matcher in one session and director in another; the task thus involved three individuals acting as director and four as matcher. In all sessions, director and matcher were sitting side by side with their respective set of photos spread out on the ground in front of them and with a low screen separating the sets. Director and matcher thus had visual access to each other but not to each others' photos. The sessions were recorded on video and total approximately 1 hour and 50 minutes.

Consistently, directors had no trouble understanding and describing the pictures, whereas matchers frequently had difficulties identifying the correct one. These difficulties may be partly attributed to the strategies used in descriptions (see below) and partly to a general unaccustomedness among consultants to the type of task-solving involved. ${ }^{3}$ The director often had to repeat his descriptions. Also, matchers were initially uneasy about making a final decision without first consulting the researcher. However, consultants gradually became accustomed as the task proceeded, and all four sessions were run to completion with only occasional errors in picture choice.

\subsection{Results}

\subsubsection{Categories of spatial reference}

As would be expected, the Jahai 'Man and Tree' sessions produced rich data of spatial reference. For the sake of descriptive clarity, it is convenient to define some general categories of such reference in the data. Thus, we can distinguish between 
picture-internal and picture-external cues. Picture-internal cues involve the tree and the man and his facets. Picture-external cues include demonstrative deixis, person deixis, landmarks, place names and relational nouns.

All the descriptions contain picture-internal cues. In particular, reference is always made to facets of the man. Such facets draw on visible inherent features in the form of body parts or body-based zones, the most common ones being 'chest', 'back', 'left' and 'right'. Occasionally other body-part terms are used, including 'shoulder', 'hand', 'forehead', 'eye', 'side', 'nose' and 'bum. One matcher prefers to combine body-part terms with a relational noun meaning 'side', e.g. 'eye-side', 'shoulder-side', 'back-side' and 'ear-side'. Reference to facets of the tree is rare and includes 'side' and 'top'. Example (1), ${ }^{4}$ involving picture R12, illustrates the use of picture-internal facets (in bold), all of which refer to the man. Note that the terms for right and left are always used intrinsically with respect to the man, and not relatively from an array-external viewpoint.
$b a=t e m$
leh $d=$ ? ${ }^{2}$ ?
tãh, ?o? hrjan ba=klapah
tem GOAL $=$ right EMP CONTR $=3 \mathrm{sG}$ this 3 s to.stand $\mathrm{GOAL}=$ shoulder right

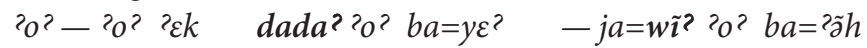
3sG $3 \mathrm{sg}$ to.give chest $3 \mathrm{sG} \mathrm{GOAL}=1 \mathrm{sG} \quad \mathrm{RT}=$ left $3 \mathrm{sG} \mathrm{GOAL}=$ here 'This [tree] to the [man's] right. It is standing at his right shoulder. He gives his chest to me. - Then his left to here.' (R12)

As can be seen in example (1), the man's facets can be used to describe his orientation to the picture-internal tree or to a picture-external cue. Sometimes such orientation is paraphrased as He is looking towards... or He is turned towards..., which imply facets but without explicitly naming them.

Unlike picture-internal cues, picture-external cues are not present in all the descriptions. However, they do occur in a vast majority of them. Looking at all sessions, the most widespread type of picture-external reference is deixis in the form of adverbial demonstratives.

This occurs rather frequently in all sessions. All of the eight demonstrative distinctions available in Jahai (see Table 1) are used in the data, and they are usually employed to give general directions in relation to the position of the participants. Thus, the speaker-anchored accessible form 'ãh 'here' typically signals orientation towards the participants on their sagittal axis from the front. The speakeranchored inaccessible form 'ani? 'there (away)' signals orientation away from the participants, usually sagittally but occasionally also laterally. The speaker-anchored exterior form 'adeh 'there (outside my side of our speech situation)' is used to describe orientation away on the speaker's side of the participants' lateral axis (or, roughly, 'away on my side'), and the addressee-anchored form ' $h \dot{i}^{2}$ ' there (outside your side of our speech situation)' symmetrically signals orientation away on the 
Table 1. The Jahai demonstrative system.

\begin{tabular}{|c|c|c|c|c|}
\hline $\begin{array}{l}\text { Main pa- } \\
\text { rameter }\end{array}$ & Oppositions & $\begin{array}{l}\text { Adverbial } \\
\text { form }\end{array}$ & $\begin{array}{l}\text { Nominal } \\
\text { form }\end{array}$ & $\begin{array}{l}\text { Referential characteristics in } \\
\text { exophoric use }\end{array}$ \\
\hline \multirow[t]{2}{*}{+ ACCESS } & Speaker-anchored & 2ãh & tãh & $\begin{array}{l}\text { Accessible to speaker (proximal, } \\
\text { perceptible, reachable, approach- } \\
\text { able, etc.) }\end{array}$ \\
\hline & Addressee-anchored & ?on & ton & $\begin{array}{l}\text { Accessible to addressee (familiar, } \\
\text { attended to) }\end{array}$ \\
\hline \multirow[t]{2}{*}{-ACCESS } & Speaker-anchored & ?ani? & $\operatorname{tani}{ }^{?}$ & $\begin{array}{l}\text { Inaccessible to speaker (distal, } \\
\text { imperceptible, unreachable, inap- } \\
\text { proachable, etc.) }\end{array}$ \\
\hline & Addressee-anchored & 2ũn & tũn & $\begin{array}{l}\text { Inaccessible to addressee (unat- } \\
\text { tended to) }\end{array}$ \\
\hline \multirow{2}{*}{ EXTERIOR } & Speaker-anchored & ?adeh & tadeh & $\begin{array}{l}\text { Located outside speaker's side of } \\
\text { the speech situation }\end{array}$ \\
\hline & Addressee-anchored & ${ }^{2} \eta \dot{t} ?$ & $\operatorname{tni} i^{2}$ & $\begin{array}{l}\text { Located outside addressee's side } \\
\text { of the speech situation }\end{array}$ \\
\hline \multirow{2}{*}{$\begin{array}{l}\text { ELEVA- } \\
\text { TION }\end{array}$} & Superjacent & 2itih & titih & $\begin{array}{l}\text { Located above speech situation } \\
\text { ('overhead', 'uphill' or 'upstream') }\end{array}$ \\
\hline & Subjacent & 'uyih & tuyih & $\begin{array}{l}\text { Located below speech situa- } \\
\text { tion ('underneath', 'downhill' or } \\
\text { 'downstream') }\end{array}$ \\
\hline
\end{tabular}

addressee's side of the same axis (roughly 'away on your side'). In the present data, all of the above forms are spatially constant with regard to the speech situation and thus independent of local topography and location of the session. Superjacent ?itith 'there (up)' indicates orientation upstream according to the local river profile, and subjacent 'uyih 'there (down)' indicates the opposite downstream orientation. In the data, these two forms are fully dependent on local river profile, and the direction of reference therefore changes in relation to the speech situation according to the location and orientation of the session. The addressee-anchored accessible form 'on 'there (you know)' and the addressee-anchored inaccessible 'ũn 'there (you don't know)', which encode the addressee's cognitive (notably attentional) relation to a referent, occur only sporadically and apparently without any fixed orientational information. This is in line with their non-spatial characteristics (cf. Burenhult 2003, forthc. a). Example (2) illustrates the use of demonstratives (marked in bold).

(2) ${ }^{2}{ }^{2} ?{ }^{2} \varepsilon k \quad k r r^{2} b a=j h \tilde{u}^{2}-k l a p a h$ tem ${ }^{2}{ }^{2}$ ba $b a n i ?$, $3 \mathrm{sG}$ to.give back GOAL $=$ tree shoulder right $3 \mathrm{sG} \mathrm{GOAL}=$ there. away klapah wĩ? ? 0 ? $b a=$ zãh, $?_{0}$ ? $?^{2} \mathcal{E} \quad b a=$ ?adeh shoulder left 3sG GOAL=here 3s to.look GOAL=there.beyond.me 
'He gives his back to the tree. - His right shoulder is there (away). His left shoulder is here. He is looking there (beyond me).' (R24)

Reference by means of person deixis, which is rather uncommon, is always used to signal orientation in relation to the participants of the task. It is expressed with first person pronouns, either singular or dual. There is also one instance of reference to a facet of first person: 'our chests'. Example (3) illustrates first person reference (marked in bold).

(3) ${ }^{2}{ }^{2}$ ? ${ }^{2} \varepsilon l \quad b a=y \varepsilon$ ? $-j h \tilde{u}^{2} b a=k r \partial^{?} \quad{ }^{2} o$ ?,$b a=h \varepsilon y \quad$ ?ăh

$3 \mathrm{sG}$ to.look GOAL $=1 \mathrm{sG}$ tree $\mathrm{GOAL}=$ back $3 \mathrm{SG} \mathrm{GOAL}=1 \mathrm{DU} . \mathrm{INCL}$ here

leh dada? ?o?

EMP chest $3 \mathrm{sg}$

'He is looking at me. - The tree is towards his back. His chest is towards us here.' (R13)

Another significant type of picture-external cue is reference to local landmarks, i.e. concrete and locationally stable entities in the surrounding environment. Such landmarks are typically represented by perceptually salient landscape (and occasionally village) features of the immediate surroundings. These features are usually located within approximately 200 meters from the site of the task, the closest one about 15 meters away. They include e.g. a house, a mountain, a trail, a stream and a waterfall. Sometimes reference is made to inherent facets of such landmarks, e.g. kuy jlmol 'top of the mountain' (literally 'mountain-head') and dada? jlmol 'mountain-side' (literally 'mountain-chest'). In other cases nouns denoting landmarks are modified by nominal demonstratives, e.g. nhjoh tit th 'that (up) ascent'. Sometimes place names are used to refer to the nearby streams (the streams of Cos and Rabah). Most landmarks are fully visible from the site of the task (e.g. the house and the mountain). In one case a landmark is not visible but clearly audible (the waterfall). Still others are just out of sight but cognitively salient in that they are significant in everyday work and movement (e.g. the trail and the river). Example (4) illustrates the use of landmarks and place names (marked in bold).

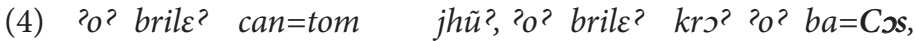
3sG to.turn SOURCE $=$ base tree 3 sG to.turn back 3 sG GOAL $=$ Cos

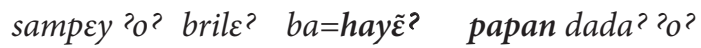
until 3sG to.turn GOAL=house plank chest 3sG 'He is turned away from the tree-trunk. He turns his back towards Cos, so that he turns his chest towards the wooden house.' (R42)

Reference is sometimes also made to more distant landscape features. These always involve the starting and end points of the nearby stream: the kuy tom 'headwaters' (literally 'water-head') and the kit tom 'river mouth' (literally 'water-bum'), 
sometimes with the relevant place name associated with the watershed (e.g. kuy Cos 'head of Cos'). In these cases, the referents are located tens of kilometers upstream and about one to two kilometers downstream respectively. Neither is visible or otherwise perceptually accessible from the site of the task. However, these referents are probably to be interpreted as signaling general (but concrete) directions or bearings rather than landmarks proper. They have close connections to the rarely occurring relational nouns krpin 'upper side' and kyom 'lower side', which also refer to general up/down direction in relation to river profile. Example (5) illustrates such reference (in bold).

(5) ba=tom jhũ? kro? ?o?, ba=kuy tom dada? ?o? GOAL=base tree back $3 \mathrm{sg} \mathrm{GOAL}=$ head water chest $3 \mathrm{sG}$

'His back towards the tree-trunk. His chest towards the headwaters.' (R24)

The Jahais' selection of landmarks for spatial reference in the 'Man and Tree' task is an ad hoc strategy. ${ }^{5}$ It is dependent on features present in the surroundings of the task and thus changes according to the location and orientation of the particular session. This becomes particularly evident in the two sessions which involve the same director. One of these sessions was run outdoors in the village, and on that occasion the director used a house, a hill, the nearby stream and the stream's mouth as his main landmark cues. In the second session, conducted upstream in the forest, he chose a waterfall, another hill and the stream's mouth and source as his main cues.

Although not representing landmarks proper, the more general directionsignaling landscape terms and relational nouns (as well as the elevation-encoding demonstratives) associated with river profile appear to be part of the same ad hoc strategy. Certainly they represent a more recurrent and stable form of reference across descriptions and sessions than individual landmarks do, but this is due to their general applicability in landscape and therefore their constant relevance in the settings of the task. Direction of the flow of water is an omnipresent cue in the mountainous and well-watered Jahai territory. Such profile-signaling reference still denotes concrete concepts and is as tied to the local surroundings as are the landmarks proper. Thus, strategies related to the notions of 'upstream' and 'downstream', although common across sessions, have referential/directional properties which may be quite different between sessions if these are run in different locations. Referentially, therefore, their employment in the task is regarded here to be just as locally dependent and ad hoc as the employment of landmarks proper.

However, reference to landmarks is not ubiquitous in 'Man and Tree' descriptions. In this respect there are some interesting differences between sessions. Whereas the three sessions conducted outdoors all contain reference to landmarks, the one conducted indoors contains none (although it does have one instance each 
of the profile-indicating relational nouns 'upper side' and 'lower side' and abundant reference by means of demonstratives, notably those forms which encode elevation, also used with reference to the local river profile). It is not clear whether the absence of landmarks terms in the indoor session is due to the lack of perceptual cues suitable for directional reference or if it is to be attributed to individual variation in solving the task. The relationship between the availability/unavailability of perceptual cues and choice of frame of reference is of great theoretical interest (Levinson et al. 2002, Li and Gleitman 2002). However, the significance of individual (and even intra-individual) variation in descriptive strategies should not be underestimated. The director of the indoor session was not tested outdoors but it cannot be ruled out that he might have chosen to disregard landmarks in an outdoor setting as well. Another possible example of such individual variation involves description of the relationship between the man and the tree: whereas two of the directors pay systematic attention to the facet relationship between man and tree, one director does so only occasionally. ${ }^{6}$

\subsubsection{The relationship between categories of reference}

Across sessions, the main Jahai strategy for solving the 'Man and Tree' task is to give two types of information involving explicit or implicit reference to the man's facets. In the majority of the descriptions this involves one picture-internal and at least one picture-external cue. Picture-internal reference expresses the relationship between the man's facets and the tree. It may take the form of a construction describing the tree's position with respect to the facets of the man (e.g. The tree is towards his back), or one in which a facet of the man is coordinated with the tree (e.g. His back is towards the tree). Although syntactically distinct (see $\$ 2.4 .3$ ), the two describe the same configuration based on the man's facets, and both therefore represent orientation (see $\$ 1.3 .5$ ). The picture-external cues are used to express the relationship between the man's facets and the surroundings, e.g. by means of deixis or landmarks.

Such two-pronged facet-based description effectively disambiguates all pictures of the game. Examples (1)-(5) all illustrate this strategy. The type of pictureexternal cue employed may vary across sessions. As we have seen, in the indoor session all such reference involves demonstrative and first person deixis and no landmarks or place names. In two of the outdoor sessions the director depends heavily on landmarks, supplemented by demonstrative and first person deixis as well as place names. The third outdoor session contains mostly demonstrative deixis but frequently also landmarks, place names and first person deixis.

Two of the sessions contain some exceptions, of two different types. In the indoor session, some descriptions involve only picture-internal reference, i.e. the relationship between the tree and the man's facets. This strategy disambiguates the 
man's orientational but not locational relation to the tree, leaving the matcher with four different possible answers (e.g. R11, R22, R33 and R44). Such ambiguity accounts for some of the difficulties participants experienced in this session in solving the task. Inversely, one of the outdoor sessions contains descriptions in which the man's facets are related to picture-external cues but not to the picture-internal tree. This disambiguates the man's orientation in the wider world but says nothing about his location or orientation in relation to the tree, again leaving the matcher with four possible answers (e.g. R11, R12, R13 and R14).

With regard to the relationship between the man's facets and picture-internal vs. picture-external cues, facets related to the man's sagittal axis (predominantly represented by 'chest' and 'back') may be used for describing his orientational relationship with the picture-internal tree as well as with picture-external cues. In contrast, facets related to his lateral axis (predominantly represented by 'left' and 'right') are used for describing the orientational relationship between man and tree but rarely between man and picture-external cues. There are occasional examples of lateral facets in the context of demonstrative or first person deixis (recall e.g. example (2)), but they are never used in relation to landmarks. Distance thus seems to inhibit the use of the lateral facets. This may reflect the inherent and body-based character of 'left' and 'right'; these cannot be projected indefinitely. At any rate, it suggests that sagittal projection is more extensible and versatile than lateral projection.

\subsubsection{Structural properties of faceted reference}

As far as the syntactic encoding of referents is concerned, there are some differences between descriptions using picture-internal cues and those using pictureexternal ones. Propositions describing the relation between the man's facets and picture-external cues always involve constructions in which the man or, more typically, a facet of the man is encoded as the syntactic subject. The picture-external cue is encoded as an oblique argument headed by the prepositional proclitic $b(a)=$, which signals GOAL. Typical examples are given in (6) and (7).

${ }^{2}{ }_{0}$ ? ${ }^{2} \mathcal{E} l \quad b=$ itith, $\quad b a=j l m o l \quad$ titih

3s to.look GOAL=there.up GOAL=mountain that.up

'He is looking there (up). At that (up) mountain.' (R32)

(7) $\mathrm{kro}^{2}{ }^{2} \mathrm{o}$ ? $b a=k i t \quad$ tom

back 3sG GOAL=bum water

'His back towards the river-mouth.' (R32)

In descriptions of the relationship between the man's facets and the picture-internal tree, however, it is usually the tree that is encoded as syntactic subject. Now 
it is the man's facet that is encoded as an oblique argument headed by the GOALsignaling prepositional proclitic $b(a)=$ (and occasionally sOURCE-signaling can= or LOCATION-signaling $k=$ ). This is illustrated in example (8).

(8) $j h \tilde{u}^{2} b a=w \tilde{\imath} ? \quad ? 0^{?}$

tree $\mathrm{GOAL}=$ left $3 \mathrm{sG}$

'The tree [is] to his left.' (R21)

However, it is also common for this relationship to be expressed in a construction where the man or a facet of his is encoded as the subject and the tree represents the oblique argument, just as in the case of picture-external cues. This is exemplified in (9) and (10).

(9) $?_{0}$ ? $\imath_{\mathcal{E}} \mathrm{\varepsilon l} \quad$ ba=tom jhü?

3 sG to.look GOAL=base tree

'He is looking at the tree-trunk.' (R33)

(10) dada? ?o? ba=tom jhü?

chest $3 \mathrm{SG} \mathrm{GOAL}=$ base tree

'His chest towards the tree-trunk.' (R11)

In summary, there are no propositions in which picture-external cues are in focus for spatial coordination with the man's facets (that is, participants do not say things like I'm in front of the man or The mountain is at his back). Instead it is the man's facets which are in focus for coordination with such cues (e.g. The man is facing me or He turns his back to the mountain). Picture-internal spatial coordination, on the other hand, involves both proposition types. The reason for these differences is likely to be found in the discourse salience of the referents. The picture-internal man and tree are recurrent referents which are constantly known and relevant. They may therefore be the most likely candidates for subjecthood. The choice of picture-external cues, however, varies with each description, making such cues less predictable and therefore more suitable as oblique arguments. This would explain the syntactic rigidity of propositions employing picture-external cues, and the more fluid pattern encountered in propositions which describe the picture-internal relationship between man and tree.

\subsubsection{Conclusions}

The Jahai 'Man and Tree' data contains evidence of systematic linguistic strategies used for spatial reference. The most pervasive feature of the descriptions is the participants' consistent and widespread employment of reference to the inherent facets of the man. Disambiguation of pictures involves information based on the spatial coordination of facets of the man with (a) the picture-internal tree and (b) a picture-external cue. Distinguishing propositions are thus invariably orientational 
in nature. Picture-external cues include landmarks, place names, relational nouns and deictic categories like demonstratives and first person. It is interesting to note that locational (that is, 'non-faceted') information with regard to the man's relation to the tree is all but non-existent in the data. This is so in spite of the fact that such relations could easily be expressed using the picture-external cues employed otherwise in the task, like landmarks, place names, demonstratives or first person. Thus, participants never say things like The man is towards us from the tree or The tree is towards the mountain from the man. Instead, information regarding the man's location in relation to the tree is just a consequence brought about by expressing two orientational relationships based on the facets of the man. In other words, one picture-internal and one picture-external orientation disambiguate the locational relationship between man and tree.

Reference in Jahai gives the impression of being very much a matter of temporary 'here-and-now', the objects in the photos being related to the surrounding environment as if they were concrete parts of it. In order to solve the task, participants incorporate in a productive way the necessary picture-external element of shared knowledge. In the absence of a conventionalized system of permanent spatial cues (e.g. in the form of abstract bearings such as cardinal directions), an efficient way of doing this is to make use of spatially informative deictic categories and perceptually and/or cognitively salient features available in the immediate surroundings of the task.

\section{Lavukaleve 'Man and Tree' data}

\subsection{Introduction to the language and its speakers}

Lavukaleve is a Papuan language spoken by some 1,700 people in the Russell Islands, a small island group in the central Solomon Islands. Lavukaleve-speaking people live a lifestyle based largely on subsistence agriculture and fishing, living in villages consisting of up to a few hundred people. The geography of the Russell Islands is dominated by the largest island of the Russell group, Pavuvu, which has smaller islands on the north and west sides, separated by sheltered sea, and open sea on the other sides.

In its grammatical structure Lavukaleve has a variety of complex predicate types interacting with a morphologically marked focus system and various categories of tense, aspect, mood and clause type to produce a rather intricate array of basic clause structures and participant-marking systems. Terrill 2003 is a grammatical description of the language. 
The first part of this section provides a brief description of spatial language in Lavukaleve. This sets the background for understanding the spatial language used in the 'Man and Tree' task, a description of which forms the second part of the section.

\subsection{Spatial reference in Lavukaleve}

In Lavukaleve, spatial reference is achieved by means of a set of directional verbs referring to a distinction between inland and seawards, as well as terms for compass points, landmarks, left and right, plus demonstratives, spatial nouns and postpositions. For large-scale geographical space, the main means of spatial expression is the directional verbs expressing an inland/seawards division. The other types of expression are generally used in smaller scales of space.

The Lavukaleve system for within-island reference makes two distinctions: a distinction between direction of movement either towards the inland or seawards, on the one hand; and on the other hand whether the movement started from the sea or from land. The following verbs are used: feu 'go inland (starting from land)', 'go up'; vau 'go seawards', 'go out'; hau 'go shorewards (starting from the sea)', 'go in'; and ve 'go' (in an unspecified direction, but by implication not inland, shorewards or seawards).

For spatial reference beyond the immediate island, there is a different system, which plots motion and location in an easterly or westerly direction, using the verbs ae 'go up/go east' and foa 'go down/go west'. Note that motion through and among the islands is expressed in terms of going up/east versus going down/west, even though the islands actually have a roundish shape; the reference of the terms is skewed to take into account the typical paths of motion through the islands. For reference to motion and location which cannot be referred to in terms of east/up or west/down, the unmarked directional verb ve 'go' is used.

These directional verbs, like other intransitive verbs which specify directional motion or position, can take a locativizer suffix $-l$, which creates an adverbial adjunct (Terrill 2003: 354) meaning 'in the location of the direction or position specified by the verb'. Thus koefale 'be bowed down', koefalel 'face down'; hau 'go shorewards', haul 'at the shore'. Note that $v e$, the unmarked directional, cannot take this suffix, as it does not specify a direction or position and hence the suffix is semantically inappropriate.

The locativizing derivation is not common or productive in everyday Lavukaleve speech. In the 'Man and Tree' task no underived directional verbs are used, but derived directional verbs do appear.

Directional verbs are not generally used for reference in small-scale space. For example, on one occasion a speaker asked her addressee for one of two identical 
objects on a table, using a deictic, and relying on trial and error on the addressee's part to identify the correct item. In the following example, the speaker is describing a photo showing a configuration of small wooden shapes in order to enable the addressee, who cannot see the photo, to assemble the wooden shapes in the same configuration: ${ }^{7}$

$$
\text { O-fufu / O-fale-va. O-fale-va. Tamu }
$$

3sG.F.o-lie.down 3sG.s-stand-PCTIMP.Sg 3sG.s-stand-PCTIMP.SG no

hoia ta tamuhoia ro o-na.

MOD.NTRL.SG.F must no MOD.NTRL.SG.F one.SG.F 3sG.F.O-in

'Lay it - stand it up. Stand it up. No, not that, it has to be on that other one.'

Occasionally speakers do use directional verbs with the locativizer for static location in small-scale space, as in the following example, but this is very much the exception. In the following example the inland/seawards terms come after various attempts on the speaker's part to explain where the sticks should go:

Iire. Leta houla hoia / o-rarava-ul ige
yes but treef. MOD.NTRL.SG.F
sisiran ta sia-re. O-tat $\quad$ o-fou-va
clearly.visible must do-NF 3sG.F.O-on.top 3sG.F.O-put.on-PCTIMP.SG
o-tat aka-ri.

3sG.F.O-on.top 3DU.s-2sG.s-lay.next.to-CAUS-ADMON/ then-PSNV Aka-ri. Feu-l hoia kanifa mailva koi then-PSNV go.inland-LOCZR MOD.NTRL.SG.F along.a.bit a.bit PL.ART also vau-l.

(inaudible) go.seawards-LoczR

'Yes. But that stick, its sides must be clearly visible. Put it on top, on top, don't lay it next to them. Like that. Like that. That's inland a bit, and the other one is seawards.'

\subsubsection{Other means of spatial reference}

Cardinal direction terms are usually used in the context of locations or directions beyond the immediate islands, out to sea. So, for example, people come from the west, canoes stand out to sea to the north, winds come from the east, and so on. These terms are used together with directional verbs when the cardinal direction specifies the goal of motion (13); but when the cardinal direction is the origin (14), a general non-directional verb of motion is used:

(13) furi a-foa

Gizo Household.

west 1sG.s-go.down place name

'... I went down west to Gizo Household.' 
(14) Aka heaka vegoaheaka nun fi o-vo.

then there.DIST east there.DIST from 3sG.N.FOC 3sG.S-come

'Over there, way over there in the east, it came from.'

Landmarks and place names are used as a means of spatial reference for expressing location, or endpoints of motion, in large-scale geographical space: he went to Baesen. They are not used as indicators of a spatial configuration, i.e. he is sitting on the Baesen side of me, or the cup is towards the tree from me.

Terms for right and left are used in everyday speech to make reference to sides of the body, typically to distinguish between right and left hands. Actually they are very rarely used at all: their most common occurrence in Terrill's corpus is in church contexts, where the phrase He is sitting on the right hand of the Father is a direct translation from English. Terms for left and right tend not to be used spontaneously in other contexts, although in the 'Man and Tree' data they are used somewhat more extensively than this.

There are a number of spatial nouns, which are a subtype of locational nouns, the class of nouns in Lavukaleve which can take locative and perlative suffixes (Terrill 2003: 161-164). They make reference to inherent facets of objects. They include the following: rolo 'inside (e.g. a cavity)'; leura 'outside'; lai 'top'; foto 'middle'; fai 'inside (e.g. a building)'; koli 'inner part'; erea 'front'; mutu 'behind'; kora 'end'; and rara 'side'. There is also a small class of postpositions expressing locations such as in, on, near, above, opposite, towards, and so on. Like spatial nouns, they make reference to the inherent facets of the object with which they are in construction. Demonstratives in Lavukaleve are complex and interesting, primarily in their nonspatial uses. In their spatial uses, there are two distance forms, proximal and distal, and there is a third, distance-neutral term, as well as a fourth, unmarked but distal term (Terrill 2003: 174-175). Demonstratives are used, particularly with the presentative suffix, to make reference to locations, accompanied by gesture. As they give very little locational information themselves, they need to be accompanied by contextual information such as a gesture or face point to make an unambiguous reference. They are frequently used in this way. In the 'Man and Tree' task they are used very little; instead speakers use terms with more specific content.

\section{3 'Man and Tree' in Lavukaleve}

\subsubsection{Set-up of the task}

'Man and Tree' data was collected by Angela Terrill in 2003. The 'Ann Senghas task' was carried out with two pairs of consultants, each person acting once as director and once as matcher, i.e. four sessions in all. In addition, another related task was carried out, a 'Man and Tree' variant called 'Game 2'. This task, which elicits 
the same types of responses as the 'Ann Senghas task', includes some pictures with identical configurations to the Senghas version and some extra pictures. Only the pictures with identical configurations to those in the 'Ann Senghas task' are included in the present analysis (called the focal set of photographs in Pederson et al. 1998: 563). The 'Game 2' task was carried out with three pairs of consultants, each person acting once as director and once as matcher, thus six sessions in all.

The tasks took place in one of two locations. The first location, used with only one pair of subjects (i.e. two sessions), was in the town of Yandina, outside a house, looking directly out to the sea, which was around 40 meters away, and the line of which was approx -30 degrees from east (i.e. slightly north of ENE). The subjects sat on chairs next to each other, with the photos between them and the sea, on the ground.

The rest of the sessions were carried out in the second location, which was in Mane Village, in the partially enclosed verandah of a leaf house. The consultants had their backs to the sea, which was about 20 meters away, and the line of the sea was approximately 80 degrees off east (i.e. ESE). The subjects sat on a bench next to each other, with the pictures on a table in front of them. All sessions were recorded on minidisk and pen and paper, and one session was also recorded on video.

\subsubsection{Results}

3.3.2.1 Categories of spatial reference. Lavukaleve directors always first establish the orientation of the man with respect to picture-external cues, such as a cardinal direction, external landmark, place name or first person (e.g. the man is facing east/the bush/Baesen/us). They then establish the location of the tree with respect to the man by means of inherent facets of the man (e.g. The tree is at the man's back) or more rarely using a cardinal direction, a landmark (e.g. The tree is on the inland side) or, even more rarely, a viewpoint-based description (The tree is across from the man). The following example of a director's description exhibits the typical information structure: a facet of the man is related to a picture-external cue, and then the tree is located with respect to the same or another facet of the man. Almost all examples conform to this information structure:

$$
\text { Ali na vegome e-hamail fi }
$$

$\operatorname{man}(\mathrm{M})$ SG.M.ART east Spec.sG.N 3sg.n.O-towards 3sG.N.FOC

o-fem o-lei. O-mutu me-hamail aka

3sG.Poss-face(N) 3sG.S-exist 3sG.Poss-backf. 1PL.in-towards then
$o$-malege-n
fi
houla la
$o$-fale-re
3sG.POSs-left-LOC 3sG.N.FOC treef. SG.F.ART
3sG.S-stand-NF 
o-lei. $\quad$ Iire.

3sG.s-exist yes

'The man's face is towards the east. His back is towards us, and the tree is standing to his left. Yes.' (R32)

Almost all the responses given consistently involve spatial coordination by means of inherent facets of the man. These are of two types: either they describe where the man is facing (i.e. relating his 'face' facet to a cardinal direction, the speaker/ addressee, a landmark or a named place); or they describe the relationship between the tree and a facet of the man, either his back, his face, or to his right, left or unspecified side.

The following faceted descriptions of the man are used: in the man's face/the man's face towards X/the man looks out to $X$; the back of the man/in the man's back; to the man's side, to the man's left and to the man's right. The expressions at the man's back and behind the man are treated as functionally equivalent, as they express the same spatial configuration between the two entities. Similarly, $X$ is in the man's face, The man's face is towards $X$ and The man looks out to $X$ are viewed as expressing the same configurational relationship, in that a facet of the man is used as the origin of a search domain in which the second element is located.

Many descriptions involve implicit reference to a facet of the man by using the verb kako 'look out' or the postposition hamail 'towards/facing. Both of these expressions invoke a facet of the man, namely his front, without actually naming it.

Note that there is a vagueness in some examples involving the postposition hamail, glossed as 'towards'. When used with objects which have an inherent front, the meaning of this word can be interpreted either as 'facing (sth.)' or as 'located towards (sth.)'. With objects which have no inherent front, it can only mean 'located towards (sth.). For example, the following description is vague between the 'facing' and the 'located towards' readings:

Ali na óase me e-hamail fi fale-re
$\operatorname{man}(\mathrm{M})$ SG.M.ART bush(N) Spec.sG.N 3sG.N.O-towards 3sG.N.FOC stand-NF o-lei, houla la o-mutuo-n

3sG.s-exist treef. SG.F.ART 3sG.POss-back-LOC

'The man is standing facing/towards the bush, the tree at his back.' (R31)

In R31, the man is on the bush side of the tree, ${ }^{8}$ and he is also facing the bush, so either reading would be appropriate. However, in the majority of cases, speakers carefully avoid the possibility of vagueness, by overtly using the body-part term 'face' or the verb kako 'look out' if they wish to indicate that the man's front is oriented towards something. If they have not specified this, then the implication is that the facing reading is not intended. There is a very clear example of this strategy: 


\section{(17) Ali na tasi me e-hamail aka o-fem $\operatorname{man}(\mathrm{M})$ SG.M.ART sea(N) Spec.sG.N 3sG.N.O-towards then 3sG.Poss-face(N) feu-l me e-hamail fi o-lei. \\ go.inland-LOcZR Spec.sG.N 3sG.N.o-towards 3sG.N.Foc 3sG.s-exist 'The man is towards the sea side and his face is towards the inland.' (R43)}

Here, the speaker clearly states that the man as a whole is towards the sea (i.e. with respect to the tree), while his face is towards the inland.

3.3.2.2 Types of cues. Typically the man is described as facing a particular cue referent, either a landmark, a named place, the speaker/addressee, or a cardinal direction.

Not all consultants use non-compass-based external landmarks. Those who do use them use them both to relate to a facet of the man and, more rarely, to locate the tree with respect to the man. Landmarks used include 'the sea', 'where the sun comes up', 'inland', 'the bush', and specific places, e.g. 'the office.' In the next example, 'the sea' is a landmark:

(18) Ali na tasi e-hamail kako-re, o-femi-n $\operatorname{man}(\mathrm{M})$ SG.M.ART sea(N) 3sG.N.O-towards look.out-NF 3sG.POss-face-LOC fi houla la o-lei.

3sG.N.FOC treef. SG.F.ART 3sG.S-exist

'The man is looking out towards the sea, the tree is in his face.' (R11)

Place names are also used. For example:

(19) Ali na vego me e-hamail fi

man(M) SG.M.ART east Spec.sG.N 3sG.N.O-towards 3sG.N.FOC

o-fem o-lei. Havun me e-hamail.

3sG.POss-face(N) 3sG.s-exist place.name(N) Spec.sG.N 3sG.N.o-towards

'The man is towards the east, his face. Towards Havun.' (R41)

Some descriptions employ first person deixis. Directors frequently say The man faces us or He shows his back to us. Such descriptions always express a binary relation between the man and first person. The speaker and/or addressee are almost never used as the viewpoint from which man and tree are related to each other.

Cardinal directions are also used, but never in descriptions such as The man is east of the tree. Rather, in all cases, they are used in relation to a facet of the man. For example:

(20) Ali na

o-fem ga furi me e-hamail man SG.M.ART 3sG.Poss-face(N) SG.N.ART west Spec.sG.N 3sG.N.o-towards 
fi o-lei.

3sG.N.FOC 3sG.S-exist

'The man's face is towards the west.' (R14)

All directors used cardinal directions, but to very varying degrees, and with highly variable levels of accuracy (see below, \$4.1.3).

There are a very few examples of responses which did not involve a description relating facets of the man to a particular cue. One rare type of such deviation is represented by a form of expression involving a picture-external viewpoint. This involves arrays in which man and tree are arranged laterally from the speaker's point of view, and is expressed either as The man is across from the tree or The tree is beside (the man). This strategy is used by two directors, twice each, and is illustrated in example (21).

(21) Fafari-l fi fale-re o-lei.

across-LOCZR 3sG.N.FOC stand-NF 3sG.s-exist

'He is standing across (from the tree).' (R42)

In this particular example, the man is to the right of the tree facing away from it. 'Across' in this context means that the array is arranged crosswise in relation to the players' sagittal axis and line of view. Similarly, in R22, the man is to the right of the tree facing it. One director says for this The man has the tree in his face, and the man is across from the tree.

Also, one example occurs where a viewpoint is used to describe the array when it is arranged sagittally to the players: one director says The man is behind the tree (R21). In this case, the man is behind the tree in the sense that the tree intervenes between the speaker and the man. However, the matcher fails to understand the description given, and the director gives a new description without appealing to this strategy. Only one director does this, and only once.

'Right' and 'left' are never used with respect to the right and left of a pictureexternal viewpoint. They are always used with reference to the inherent right and left of the man. In Lavukaleve, these words are obligatorily possessed by their head noun, in this case the man, so there is no room for ambiguity. For example:
Ali na
ngo-hamail fi
$o-f e m$
o-lei,
$\operatorname{man}(\mathrm{M})$ SG.M.ART 2sG-towards 3sG.N.FOc 3sG.Poss-face(N) 3sG.s-exist
o-lounage- $n$
fi
houla la
o-lei.

3sG.POSS-right.side-LOC 3sG.N.FOC treef. SG.F.ART 3sG.s-exist

'The man's face is towards you, the tree is to his right.' (2.08/R12)

No other descriptions utilizing a picture-external viewpoint occur. 
Similarly, descriptions which rely on abstract bearings in locating the objects in relation to each other are only present to a minor extent in the Lavukaleve data. Two directors say The tree is on the bush/sea side of the man (in a total of 5 tokens) and one says The man is on the sea side (of the tree) ( 1 token). In the following example such a locating proposition is combined with an orientational description:

(23) Ali na feu-l me e-hamail $\operatorname{man}(\mathrm{M})$ SG.M.ART go.inland-LOCZR Spec.sG.N 3sG.N.O-towards kako-re, o-malege-n tasi-n e-hamail look.out-NF 3sG.POss-left-LOC sea-LOC 3sG.N.O-towards houlafeo fale-re o-lei. Iire. treef. 3sG.F.FOC stand-NF 3sG.s-exist yes 'The man is looking out towards inland, on his left towards the sea is a tree standing. Yes.' (R41)

\subsubsection{Structural properties of faceted reference}

The two-part expressions found in Lavukaleve 'Man and Tree' descriptions invoke two different sentence structures. The first part of most descriptions is a statement orienting the man with respect to a picture-external object. Such sentences always encode the man as subject, and the picture-external cue as an oblique locational adjunct, the exact type depending on the syntactic category of the content word of the adjunct. The verb is typically an existential predicate. Lavukaleve clauses are typically coded overtly for their information-structure properties by means of a series of focus markers, and these first parts of the two-part 'Man and Tree' descriptions typically have focus marked (with focus marker $f$ ) on the locational adjunct, the part that expresses where the man is oriented towards. For example:

Ali na o-fem $\quad g a \quad$ furi me
man(M) SG.M.ART 3sG.POSs-face(N)
e-hamail $\quad f i \quad c$-lei.

3sG.N.O-towards 3sG.N.FOc 3sG.s-exist

'The man's face is towards the west.'

The second part of the typical two-part expressions normally consists of the tree encoded as subject, with the entity which the tree is located with respect to expressed as a locational adjunct. This adjunct is almost always a body part or other facet of the man, and is expressed syntactically as a noun possessed by the man. The predicate structure is a clause chain consisting of a medial verb 'stand', followed by an existential predicate as final verb. In these expressions, the focus is once again typically marked overtly and falls on the locational adjunct, which, as in the previous example, is the information which changes for each picture, while the tree and the man themselves remain constant. 
Akao-malege-n fi houla la fale-re o-lei.

aka 3sG.Poss-left-LOC 3sG.N.Foc treef. sG.F.ART stand-NF 3sG.s-exist 'And the tree is standing on his left.'

\section{Jahai, Lavukaleve and frames-of-reference analysis}

The initial goal in collecting and analyzing the Jahai and Lavukaleve data was to ascertain the frame or frames of reference used in these two languages. Seen from the viewpoint of conclusions drawn in previous analyses, much of the data for both languages can be assigned unproblematically to the intrinsic frame of reference. That is, all the propositions in which man and tree are spatially coordinated with each other by means of the man's facets (explicitly or implicitly) belong to the intrinsic frame of reference. This includes e.g. Jahai expressions like The tree is at the man's right shoulder and His back towards the tree, or Lavukaleve expressions like The tree is to the man's left and The tree is in the man's face.

Also, most previous commentators agree that reference to the deictic center in the form of first person may be used within the intrinsic frame of reference (Levinson 1996: 138, Danziger 1997: 62, Pederson et al. 1998: footnote 16, Palmer 2002a: 111, Levinson 2003: 71, Pederson 2003: 289, Schultze-Berndt, 2006: 110). That is, in propositions like The man is facing me or The man is in front of me, the relationship between ego and the man is binary and may be based on inherent facets of either of them. Jahai and Lavukaleve propositions like The man's back is to us and He is looking at me are therefore readily assigned to the intrinsic frame of reference.

However, there are several strategies in both languages which do not immediately lend themselves to straightforward frames-of-reference classification. Some of these involve cues which have proved problematic in previous accounts as well, such as landmarks. Others involve cues which as far as we know have not been dealt with in previous work based on 'Man and Tree' data, especially demonstratives. Still other proposition types have been unproblematically dealt with in previous analyses but present particular problems in the present data in terms of how to correctly analyze their cues, notably cardinal directions. These problematic cases are outlined in more detail below.

\subsection{Problems with cues}

\subsubsection{The Jahai demonstratives}

The frequent employment of adverbial demonstratives as orientational cues in the Jahai 'Man and Tree' descriptions is an interesting and little-discussed strategy which calls for a more general treatment of the role of deixis in frames-of-refer- 
ence typology. Recall that previous analyses have treated reference to the deictic center in the form of first person as intrinsic. Thus, a proposition like The man is facing me is unequivocally intrinsic since it describes a binary relation between man and ego based on the inherent facets of the man. But so far the argument has not been taken further.

However, if first person deixis can be uncontroversially analyzed within the intrinsic frame of reference, this frame should also be able to handle person deixis which does not represent the deictic center. On that account, propositions like The man is facing you and The man is facing her are equally classifiable as intrinsic.

Does the same hold true for other deictic categories, like demonstratives? Demonstrative deixis, of course, is analogous to person deixis in that it can represent either the deictic center or something that is not the deictic center. Pronominal demonstratives like 'this' and 'that', which typically represent concrete entities, should present no problems to such an intrinsic analysis. It would also seem to be possible for more general location-signaling demonstratives of the type 'here' and 'there' to be used. Although these are referentially less well-defined, they can be argued to represent concrete locations and therefore to be employable e.g. as Ground in an intrinsic relation. From the point of view of Ground status, there seems intuitively to be no essential conceptual difference between 'me', 'he', 'it', 'that' and 'there'. It will therefore be suggested here that Jahai propositions of the type He is looking here and His right shoulder is there (away) are intrinsic descriptions. Clearly, however, such descriptions draw on viewpoint-like cues and are not straightforwardly separable from the relative frame of reference.

Jahai propositions which involve the so-called exterior demonstrative distinctions are particularly interesting. These distinctions can be argued to represent in themselves a frame of reference (Burenhult, forthc. b). This is because they invoke a coordinate system involving the projection of angular search domains in which the referent can be found. The speech situation itself (the deictic center made up of the two interlocutors and the space between them) represents a solid entity in the minds of Jahai speakers, and speaker and addressee are in effect conceived of as asymmetries (that is, facets) of that entity. The employment of an exterior demonstrative to refer to an object then serves to spatially coordinate in a binary way this object with the asymmetries of the 'speech situation entity' (cf. \$2.4.1). This view of the spatial constellation is distinctly intrinsic (and orientational). So when a Jahai 'Man and Tree' player describes a scene as The man is looking there (towards outside my side of our speech situation), he establishes a complex spatial set-up which involves a region located in relation to a facet of the speech situation, to which the man is orientationally related. Here, one proposedly intrinsic description is mapped onto another spatial constellation which is also intrinsic, the identities of Figure and Ground being different in the two representations. 
Suffice it to say that, in the 'Man and Tree' context, exterior demonstratives, and deictic cues in general, do not easily lend themselves to uncomplicated assignment to a particular frame of reference.

\subsubsection{Landmarks and axes}

There is uncertainty in the frames-of-reference literature on the treatment of landmarks. Senft (2001: 539-540) suggests that ad hoc landmarks are part of absolute systems; others convey the impression that such landmarks represent an intermediate system between intrinsic and absolute (Levinson 1996: footnote 35, 2003: 49, 81, Levinson et al. 2002: 173, Pederson 2003: 290-291). Levinson says "there are reasons for thinking that landmark systems and fixed-bearing systems [i.e. absolute systems -AT/NB] are distinct conceptual types" (Levinson 1996: footnote 35).

Pederson raises the possibility of landmarks being treated as operating within the intrinsic frame of reference: "Of course, locating by directional reference to perceptual landmarks is akin to locating by projecting from the intrinsic features of a ground object. In both cases there is a direction determined from the ground on the basis of perceptually available features. The difference being that in one case the features belong to the ground and in the other case they do not" (Pederson 2003: 290). Pederson explicitly mentions the Balinese system (described in Wassman and Dasen 1998) as "a good candidate for an intermediate case between local landmarks and an absolute coordinate system" (Pederson 2003: footnote 2).

The reason landmarks present a murky area in the frames-of-reference literature is that they challenge categorization based on concrete vs. abstract and ad hoc vs. conventionalized spatial cues. Their degree of concreteness and conventionalization appears to vary across different languages: in some languages they can readily be thought of as interconnected with other landmarks, forming vectors which abstract away from actual geography, while in other languages this is not the case at all.

In Jahai, landmarks employed in the 'Man and Tree' task are consistently ad hoc and concrete, and sometimes involve objects within very close proximity to the setting of the task. The more general direction-signaling cues based on local river profile (which surface as landmarks, relational nouns or demonstratives) represent a more recurrent family of strategies. But although not always representing landmarks proper, such cues are argued here to be just as concrete and locally dependent as are landmarks. They cannot even be claimed to represent conventionalized cues because they are not employed systematically within or across sessions, other than as one of many strategies. Also, they seem to be easily overridden by other cues, including landmarks, if such cues are perceived as more salient in the particular setting. So, in Jahai, there is no motivation for treating landmarks and bearings as fundamentally separate systems of spatial reference. Their concrete 
and ad hoc nature would seem to favor the intrinsic over the absolute interpretation, but it is difficult to operationalize this distinction.

A related issue in Lavukaleve is the inland/seawards distinction. For some authors (e.g. Hill 1997, Palmer 2002b) the inland/seawards distinction is considered an axis, and in many languages of the Pacific in particular it operates in opposition to a second axis based on the cardinal directions east/west. However, there is some question over whether inland/seawards is actually an abstract axis at all.

Levinson says on this point, "Absolute directions give us external bearings on an array, but without employing viewpoints. They are 'allocentric' systems. Local landmarks can give us some of the same properties, especially within a restricted territory, but they do not have the same abstract properties as notions like 'north'. The point is made vividly by many Austronesian island languages which fix an east-west axis by reference to the monsoons, but use a 'mountain'-'sea' axis to contrast with it. As one moves around such islands, the one axis remains constant, the other rotates" (Levinson 2003: 90).

However, the 'mountain'-'sea' axis only moves if one is thinking in terms of compass points. The axis is not a line traveling along the island with one point fixed in the middle and one swinging around the beach. Rather, the axis can be thought of as an infinite number of lines radiating out from the center of an island, in the same way that a compass direction can be thought of as an infinite number of parallel lines. It is misleading to think of such an axis as 'moving', as opposed to 'fixed' axes like those created by cardinal directions. Thus it is not clear how, if at all, an axis of this sort differs in terms of abstract geometrical properties from cardinal axes. In this sense, there is no a priori reason why an inland-seawards axis cannot be a real absolute axis (see also Palmer 2002b on this point).

A much more specific problem arises in Lavukaleve regarding whether the inland/seawards division is best treated as an abstract axis. As we saw, Lavukaleve has an inland/seawards distinction, expressed in the Man and Tree data by means of derived motion verbs functioning as locational adjuncts. The issue centers around whether these derived verbs are to be interpreted as expressing an abstract absolute vector, or rather whether they are best seen as two opposed concrete landmarks. Evidence in favor of the abstract-axis analysis is that the verbs used to express these distinctions refer to movement along a line; this line, then, could be thought of as an axis. Against this analysis, however, is the fact that the terms do actually refer to concrete places: the sea, and the bush. In the Austronesian language Longgu, Hill (1997) finds a morpho-syntactic distinction between the 'sea' term when it is used as a place and when it is used as one end of an abstract axis. For Lavukaleve and other languages, like Kilivila, similar evidence does not exist. Senft (2001: 545) discusses this problem for Kilivila, arguing that while a land-sea axis can be said to exist in Kilivila, other landmarks 
occur just as readily, and on the basis of frequency one would not want to privilege the land-sea distinction as an axis at the expense of other terms. Note here the clear parallel to the usage of landmarks and directions based on river profile in Jahai.

The critical issue is that if the inland/seawards distinction is indeed an abstract axis, then it would conventionally be considered a feature of the absolute frame of reference; if not, then the terms for seawards and inland are presumably to be thought of as landmarks, in which case their functioning in the absolute frame of reference is no longer clear.

What is lacking in the theoretical discussion is a way to operationalize this distinction between true abstract axes on the one hand and concrete landmarks on the other. It is as yet unclear whether this should be done on a language-bylanguage basis, or in more general theoretical terms.

\subsubsection{Cardinal directions: Abstract or concrete?}

A related problem arises with bearings in the form of cardinal directions. These are by definition abstract, forming interlocking axes based on abstract geometrical properties. However, in Lavukaleve at least, and possibly in other languages, cardinal directions are not good examples of abstract interlocking axes. Section 3.3.2.2 described the use of Lavukaleve cardinal directions in the 'Man and Tree' sessions, but it is important to note that they are used and understood to varying degrees among different speakers. North is the most frequently used compass point, its use by far exceeding that of any other compass point, followed by east. South is the least used, with west only slightly more frequent.

Significantly, most speakers do not seem to control all compass points to an equal degree. One director used west correctly, but north, east and south incorrectly. Two directors only used north, but used it incorrectly every time. One director only used east and south, both correctly. One director only used south, also correctly. Only one director used all four compass points, using them correctly every time. The fact that there are equal numbers of pictures for each cardinal direction in the 'Man and Tree' task, and yet the cardinal direction terms are not used to an equal degree, and further that some directors never used the full set of four cardinal directions, suggests that the four terms are not conceptualized as a closed and interlocking system by most directors. It suggests, rather, that for most speakers each of the terms exists separately, not necessarily in opposition to its counterpart, or to the terms forming the other axis. This suggests in turn that the terms do not represent abstracted axes at all, but rather are alternative names for generalized directions, possibly based on landmarks.

On a number of occasions, players discuss uncertainty over compass points, and in many cases they overtly equate compass directions with landmarks. For 
example, in the following exchange (translated from Lavukaleve), $\mathrm{H}$ asks $\mathrm{B}$ where south is, to which B gives a landmark reference (he says 'towards Havun'):

(26) R43:

B: The man is standing facing his face south. And the tree is to his left.

$H$ : South? Where is that?

(H points at wrong picture)

B: No. I said south! Towards Havun! His face is there [lit: his face exists], and the tree is standing on his left.

( $\mathrm{H}$ points at correct picture)

B: Yes.

Later $\mathrm{H}$ asks where north is; when she questions $\mathrm{B}$, he once again responds with a landmark ('in the direction of the office'):

(27) R23:

B: The man is towards the north, standing there. His face. And the tree is on his right side.

H: North?

B: I said north. His face is towards the office. The tree is on his left.

So for Lavukaleve speakers, it is doubtful that compass points form a neat abstracted pair of interlocking axes. Knowing the direction of one compass point does not automatically enable a speaker to work out where the other compass points are. It seems, rather, that they are known singly in relation to obvious landmarks, and that they can best be seen as a type of landmark themselves. They are less concrete than expressions such as 'mountain', but they are nonetheless tied to concrete landmarks, and take their reference from concrete landmarks. For Lavukaleve speakers in particular, compass points do not really represent abstract bearings, but operate in a way similar to landmarks.

One possible analysis of this is that the glosses given for the Lavukaleve terms are misleading. If we reserve glosses like 'east', 'north', 'south' and 'west' for truly abstract geometrically-derived cardinal directions, then possibly these are not the best glosses for the Lavukaleve terms. However, for the majority of speakers they do seem to correspond to English compass terms, and thus the glosses remain a good enough fit. The truth is that the Lavukaleve terms probably lie somewhere between genuine abstract cardinal directions, and genuine concrete landmarks.

The underlying issue for cardinal directions, in Lavukaleve and indeed in other languages, is whether they function within a particular spatial reference system abstracted from everyday reference, and if so, how abstract does abstract have to be? If they are abstract, they would conventionally be assigned to the absolute frame of reference. If they are not very abstract, and/or they do not form axes, then 
they should be considered more as landmarks, and in this case they could possibly function within the intrinsic frame of reference. But as shown in $\$ 4.1 .2$, the treatment of landmarks in the frames-of-reference literature is itself very unclear.

\subsection{Orientational rather than locational configurations}

So far the discussion of problems with conventional frames-of-reference typology has focused on issues dealing with types of cues used and how these should be interpreted. But it is becoming increasingly clear that a more overarching concern is the nature of the spatial configuration expressed, quite apart from the cues used to express it.

Previous frames-of-reference analyses have been primarily concerned with the 'standing' (see $\$ 1.3 .5$ ) aspects of spatial descriptions in the 'Man and Tree' task and the disambiguation of transverse relations. That is, they have focused on how languages place the two objects with respect to each other, and conclude that this can be achieved by means of an external viewpoint (relative), an abstract bearing (absolute) or an inherent facet of the man (intrinsic). With such a focus on the placing of objects, the relative and absolute frames of reference come out as the most efficient and unequivocal strategies. On the other hand, a purely intrinsic strategy, which relies only on the two objects themselves and their inherent facets, is unable to fully solve the 'Man and Tree' task.

In both Jahai and Lavukaleve, however, it has become clear that descriptions do not 'locate' according to the definition of the term employed in this paper. Virtually all propositions involve the spatial coordination of facets of the man with cues of various sorts, including the picture-internal tree as well as picture-external cues like first person, demonstratives, landmarks, place names, relational nouns, abstract bearings and so on. Therefore, Jahai and Lavukaleve descriptions do not locate objects - they orient them. Location does not even seem to be the primary purpose of descriptions: what Jahai and Lavukaleve speakers do is produce orienting descriptions which have the eventual (and emergent) property of locating.

But the orienting strategy is in fact highly suited to the task. All pictures of the 'Man and Tree' task can be disambiguated from each other by means of two orienting descriptions: one which orients the man to the tree, and one which orients the man by means of a picture-external cue. This is exactly what most Jahai and Lavukaleve descriptions do. Indeed, it is impossible to solve the task purely by locating; one can locate the man and the tree with respect to each other, but one still needs to orient the man.

Viewed in this way, the diverse range of picture-external cues are all part of a very systematic and consistent strategy, one in which the identity and characteristics of the cues, so central to conventional frames-of-reference analysis, are far 
less significant. Importantly, Jahai and Lavukaleve are radically orientational even though the cues they use for orientation could just as well be used for location. Landmarks, for example, could well be used to create locational descriptions like The man is riverwards of the tree or The tree is towards the mountain from the man or even The man towards the river and the tree towards the mountain - but this is not what happens. Instead, landmarks are consistently used for spatial coordination with the facets of the man, and they orient the man in relation to the wider world. In doing so, each landmark forms part of a distinct orientational relation involving itself and the man, but not the tree. The same holds for other types of cues, from deixis to cardinal directions.

Given this potential of cues to form part of locational descriptions, the reluctance on the part of Jahai and Lavukaleve 'Man and Tree' players to employ locational strategies leads us to believe that 'orientation' and 'location' are conceptually very different approaches to spatial description.

\subsection{Summary}

From the point of view of conventional frames-of-reference typology, Jahai and Lavukaleve come across as rather mixed and unsystematic, employing largely the intrinsic frame of reference, but also the other frames. Some expressions may not be analyzable within the frames-of-reference domain at all. Analytically problematic categories of cues include demonstratives, landmarks and cardinal directions.

But this picture falsely conceals what is in fact an underlying unity. The overriding consideration for Jahai and Lavukaleve is that descriptions used in 'Man and Tree' are orientational. That is, they rely almost exclusively on the spatial coordination of facets of the man with cues of various kinds. This has little to do with the abstractness/concreteness of the cue referents, nor with their ad hoc vs. conventionalized nature, issues which are practically unresolvable in any case.

Are Jahai and Lavukaleve unique in their uniformly orientational strategy? The following section reexamines some of the languages studied in previous descriptions.

\section{Beyond Jahai and Lavukaleve: Orientation as a super-strategy}

Pederson et al. (1998: 569) conclude that Kilivila (Austronesian, Trobriand Islands, Papua New Guinea) and Mopan (Mayan, Central America) are fundamentally distinct from the other languages in their sample on the basis of the lack of information in these two languages "about transverse relations other than that which was actually about features of the figure and ground" (see also Danziger 1999: 89-93, 
Senft 2001: 532). This is seen as symptomatic of an intrinsic frame of reference. The authors refer specifically to strategies expressing the relationship between man and tree. However, they also consider the Kilivila and Mopan strategy of relating the man's inherent facets to first person (i.e. to the participants of the task, e.g. The man is looking at me) as representing an intrinsic frame of reference (Pederson et al. 1998: footnote 16).

In a separate account of Kilivila 'Man and Tree', Senft (2001: 532-540) shows in more detail how players prefer an intrinsic frame of reference in relating man and tree to each other and how they also use deixis in the form of first person reference. Moreover, in other photo-matching games run in the Kilivila setting, players also make use of picture-external ad hoc landmarks which Senft (2001: 539-540) suggests may possibly represent an absolute frame of reference.

For comparative purposes we examined the Kilivila 'Man and Tree' transcriptions (with the kind help and permission of the collector, Gunter Senft). We agree with Senft (2001) and Pederson et al. (1998) that the descriptions are of a mixed nature but essentially seem to be most closely associated with the intrinsic frame of reference. In fact, if viewed with the same approach as that taken to describe the Jahai and Lavukaleve data presented here, the Kilivila data comes out as consistently orientational. Distinguishing propositions always involve reference to facets of the man, which are used to coordinate him with either the tree or first person according to the now-familiar pattern. A typical example is given in (28).

(28) la-bani te-tala tau la kaitukwa o kakatae kai o 1.PAST-find CP.man-one man his walking.stick LOC right and tree LOC la kikivamae tubulo-la e-mikeya-gu his left and back-his 3-come-towards-me 'I found one man (with) his walking stick at the right and (a) tree at his left, and his back points towards me.' (Senft 2001: 536)

The material in this dataset does not contain examples of distinguishing propositions describing the array without reference to facets, i.e. there is a total lack of descriptions which may be interpreted as locational. In this respect, Kilivila players are more consistent in their orientational strategy than Lavukaleve players are, for example. Although ad hoc landmarks are absent as cues in the 'Man and Tree' data from Kilivila, they appear in profusion in another photo-matching game involving pictures of two men (Senft 2001: 539-540). Again, as far as we can determine from examining the original transcriptions, these landmark cues are typically used in relation to the men's facets and are therefore part of the same orientational strategy. An example is given in (29). 


\section{(29) so la-nagi te-yu tauwaumata-si e-la o}

friend 1.PAST-choose cP.man-two men eyes-their 3-go LOC bwalitasi kaitukwa o kakata

sea their walking.sticks Loc right

'My friend, I chose two men, they look towards the sea, their walking sticks (are) at the right.' (Senft 2001: 541)

'Man and Tree' data from the other language dealt with as intrinsic in previous frames-of-reference typologies, Mopan, is analyzed in detail in Danziger 1997, 1999. Mopan is described by Danziger as employing two strategies in solving the task: 'Scene-Internal information' and 'Self-as-Ground'. The former involves relating the man to the tree by means of facets of the man; the latter involves the relationship between the man's facets and the participants in the task (Danziger 1999: 88). It is made clear that both 'Scene-Internal' reference and 'Self-as-Ground' make use of binary relationships between Figure and Ground, and that information external to the scene is absent. Examples (30) and (31) illustrate the typical Mopan pattern.

$K a^{\prime} a-k a^{\prime}-k a ̈ x-t-e^{\prime}$

a nene' $t z^{\prime} u b^{\prime}$

CONJ 2ACTOR-again-seek-TR-SUBJ_3UNDERGOER ART little child
a... t-u-taian
ke'en- $\varnothing$
top'-o

ART at-3POSSESSOR-chest be_located-3UNDERGOER bush-ECHO

'You should find the little child again who ... has the bush at his chest.'

(Danziger 1997: 66, Pederson et al. 1998: 570)

(31) Käx-t-e a tz'ub'a... chun-pach a tun-cha'an waye'-ji

seek-TR-SUBJ DET child DET only-3A-back DET DUR-3A-look DX1-SCOPE

'Find the child who... only his back is looking here.' (Danziger 1999: 89)

Scene-internal reference is shown to be overall the more common of these two strategies in terms of number of distinguishing propositions (Danziger 1999: 91). Here Danziger (1999: 99) finds interesting gender differences, however: whereas female Mopan players employ scene-internal reference almost twice as often as they use first person as Ground, male players use the two strategies equally often.

Another interesting case in point is Jaminjung (non-Pama-Nyungan, northern Australia). This language has directional terms, expressed in terms of water flow of the local river system on one axis, and verticality on the other (SchultzeBerndt, 2006: 104-107). However, these directional terms are usually used only in large-scale space, and only to indicate location of a place or entity relative to the deictic center; to refer to direction of motion; or else to indicate direction of gaze or orientation of a faceted Figure. What is interesting to our discussion is that " $[t]$ he direction terms are never used in order to locate a figure with respect to a 
ground which is not the deictic center, i.e. a ground that has to be made explicit as the reference point (e.g. 'the man is downstream of the tree')". Rather, in smallscale space such as that elicited by the 'Man and Tree' task, the terms are only used to describe the orientation of a faceted Figure.

The following Jaminjung example comes from the photo-photo matching game involving two men rather than a man and a tree:

janyungbari ngiyina-wurla ga-yu=ni juwiya,

other PROX-DIR 3sG-be.PRS=SFOC nose

janyungbari manamba-ngining ga-yu

other upstream-L.ALL 3sG-be.PRS

'(there are two men,) one has his nose that way, the other is facing upstream' (Schultze-Berndt, 2006: her example (72))

Schultze-Berndt states explicitly that "in descriptions of small-scale arrangements, only orientational information is given in absolute coordinates, while 'standing' (placement) information is given in terms of intrinsic coordinates". She goes on to say that "[e]xpressions of this type are based on an intrinsic frame of reference in the sense that they semantically incorporate an intrinsic feature of the figure, but the orientation itself can, in principle, be indicated (i) with respect to an absolute direction ... (ii) with respect to a landmark ... (iii) with respect to a relative frame of reference (e.g. 'the man is facing left', not found in Jaminjung data), or (iv) with respect to a ground (which may also be the deictic center...)" (Schultze-Berndt, 2006: 109).

Jaminjung, then, is similar to Lavukaleve in its orientational use of what are typically seen as "absolute terms"; in the case of Jaminjung, these are directional terms relating to water flow and verticality, while in the case of Lavukaleve they are cardinal direction terms.

It appears that Yélî Dnye (Papuan isolate, Rossel Island, Papua New Guinea) largely shares these characteristics. In Levinson's account, Yélî Dnye speakers structure their 'Man and Tree' responses by giving “'facing' (orientational) information in absolute coordinates (man facing south), and then giving the 'standing' (placement) information in terms of intrinsic coordinates (man confronting tree)" (Levinson, 2006: 186). ${ }^{9}$ This is very similar to what Jaminjung speakers do.

Furthermore, 'Man and Tree' data was recently collected by Burenhult from Semnam (Mon-Khmer, Peninsular Malaysia). Preliminary analysis shows that speakers of this close relative of Jahai also make consistent use of orientational descriptions, employing demonstratives, first person and reference to local landmarks.

To recapitulate, the Kilivila and Mopan strategies of solving the 'Man and Tree' task are identical in the following respect: speakers of both languages strictly adhere to a pattern of spatial reference which is limited to orientational relations between man and tree and between man and first person. This pattern is more 


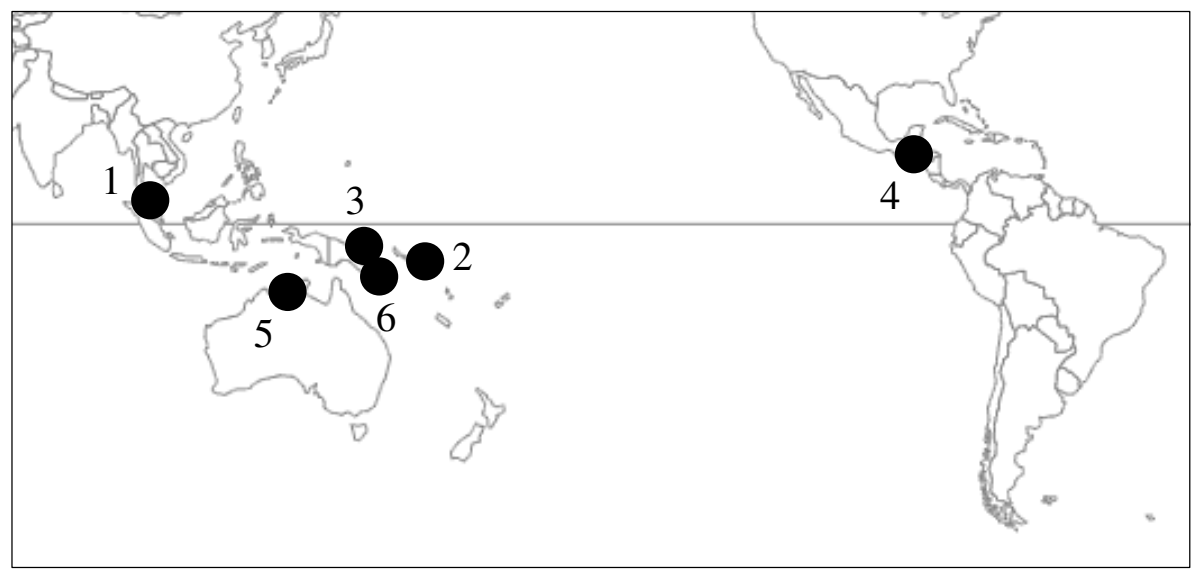

Map. Languages discussed in the text: 1. Jahai and Semnam, 2. Lavukaleve, 3. Kilivila, 4. Mopan, 5. Jaminjung, 6. Yélî Dnye.

focused and limited in its number of cues than the more diverse strategies of cue use employed by speakers of Jahai, Lavukaleve, Jaminjung, Yélî Dnye and Semnam. However, we propose here that all these languages are united in adhering to an orientational 'super-strategy' of spatial reference which makes universal use of facets in relating an entity to a cue. The way the languages differ is in what types of cues are employed to create such spatial relations. They all also employ picture-external cues, but whereas Kilivila and Mopan speakers only go so far as to use themselves as cues in an orientational relation with the man, Jahai, Lavukaleve, Jaminjung, Yélî Dnye and Semnam speakers also employ other cues, such as demonstrative referents, relational nouns, landmarks, place names and cardinal directions (recall also the Kilivila use of landmarks in other photo-photo matching games). ${ }^{10}$

How do we account for this internal diversity of orientational reference? Why do languages like Kilivila and Mopan restrict themselves to two types of cues whereas languages like Jahai, Lavukaleve, Jaminjung, Yélî Dnye and Semnam draw on a wider range of cues? In particular, which factors determine or influence players' choice of cue? Obviously this is a complex issue and it is not the purpose of this study to explore it in detail. However, it would be reasonable to assume that the availability or unavailability of perceptual cues in the environment surrounding the task may have an influence on the usage of e.g. landmarks, as was cautiously suggested for Jahai. Recall the absence of landmarks in the one Jahai session run indoors. Note also the lack of landmarks in the Mopan 'Man and Tree' data, all sessions of which were conducted indoors (Danziger, personal communication). A range of other contextual factors are also likely to be potentially significant, such as the players' familiarity with the surroundings and each other. Other differences in the set-up of the task, such as the presence or absence of a screen between director 
and matcher, should also not be ruled out as an influencing factor. For example, David Wilkins (personal communication) suggests that a screen between the players will inhibit the use of deictic cues.

Furthermore, differences between the languages are also likely to result from the fact that they have different linguistic means at their disposal. Jahai, for example, has a spatially very informative system of demonstratives, which is indeed extensively employed in the task. Other languages with weaker spatial connotations in their demonstratives are less likely to employ this strategy. Lavukaleve has cardinal direction terms, and these are employed in the task. Needless to say, languages without cardinal direction terms will not use this strategy.

\section{Conclusion}

This work has identified a group of genetically and geographically diverse languages which rely almost exclusively on what is referred to here as an 'orientational' strategy in disambiguating the coordinate spatial relations of the 'Man and Tree' task. Throughout the data, spatial description consistently involves the relationship between the facets of an entity and a cue of some form. Accordingly, these languages do not employ independent cues to impose external coordinates on the two entities of the 'Man and Tree' array and thus do not describe location. The consistency in these languages in favoring the 'orientational' strategy over a 'locational' or mixed strategy leads us to believe that these represent fundamentally different systems of spatial relations. It is descriptively appealing to think of orientation as the organizing principle behind spatial description in these languages.

In conventional frames-of-reference analysis, 'orientational' languages like Jahai and Lavukaleve will always come out as internally and cross-linguistically diverse and unsystematic in their employment of spatial cues. Recall also that Kilivila and Mopan were characterized by Pederson et al. (1998: 569-570) in terms of their non-use of a particular spatial distinction. In sharp contrast, the integrated orientational analysis proposed here brings out the uniformity, systematicity and true genius of these superficially motley and/or functionally restricted systems of spatial reference.

As the initial impetus for this discovery arose from within the framework of frames-of-reference typology, the question arises of how the orientational strategy is to be related to conventional typologies of spatial frames of reference. Recall that current theories of frames of reference distinguish three such frames - absolute, relative and intrinsic - and that previous analyses have separated 'standing information' from 'facing information'. Although this earlier work has been largely concerned with typologizing different forms of 'standing information', it is clear that 
both standing and facing information has been considered to be employed in all three frames of reference. From the viewpoint of conventional frames-of-reference analysis, then, perhaps the most immediate and natural interpretation of the orientational strategy described here is that it forms a distinct system of spatial reference which operates across frames of reference. If so, we have identified a group of languages which do not primarily converge on frames of reference in solving the 'Man and Tree' task but prefer to conventionalize spatial description along a different dimension. Another possibility would be a more thorough integration of orientation into the existing frames-of-reference edifice, and an attempt at equating it with the intrinsic frame. However, this is difficult to achieve within the confines of our current understanding of frames of reference (see Burenhult and Terrill, in prep).

Whatever one is to make of frames of reference in these languages, we believe we have shown that, at least for the languages investigated here, a more revealing and justified analysis is one which takes orientation, or spatial coordination by means of facets, as its primary structural principle.

\section{Notes}

* This research was supported by the Max Planck Society, the European Science Foundation under their EUROCORES program 'Origin of Man, Language, and Languages', a European Community Marie Curie Fellowship, and a Volkswagen Foundation DoBeS grant. The authors are solely responsible for information communicated and the European Commission is not responsible for any views or results expressed. We are grateful to Eve Danziger, Michael Dunn, Orin Gensler, Daniel Haun, Steve Levinson, Asifa Majid, Eric Pederson, Eva Schultze-Berndt, Gunter Senft, Ann Senghas, Claudia Wegener, David Wilkins, and two anonymous reviewers of Studies in Language for their helpful input. We are especially grateful to Gunter Senft for sharing his Kilivila 'Man and Tree' transcriptions with us. Special thanks are also directed to the Lavukal community, Solomon Islands, and the Jahai and Semnam communities, Peninsular Malaysia. The authors contributed to this paper equally.

1. The protocol varies slightly between different 'Man and Tree' reports.

2. 'Spatial coordination' refers in this paper to the general process of establishing spatial relations between cues.

3. Senft (2001: 532-540) reports on similar difficulties with Kilivila consultants and offers a critique of the 'Man and Tree' task.

4. The following abbreviations are used in this paper:

$\begin{array}{llll}1 & \text { first person } & \text { LOC } & \text { locative } \\ 2 & \text { second person } & \text { LOCZR } & \text { locativizer } \\ 3 & \text { third person } & \text { M } & \text { masculine } \\ \text { A } & \text { agent } & \text { MOD } & \text { demonstrative modifier }\end{array}$




$\begin{array}{llll}\text { ADMON } & \text { admonitive } & \text { N } & \text { neuter } \\ \text { ALL } & \text { allative } & \text { NF } & \text { non-finite } \\ \text { ART } & \text { article } & \text { NTRL } & \text { neutral } \\ \text { CAUS } & \text { causative } & \text { O } & \text { object } \\ \text { CONJ } & \text { conjunction } & \text { PAST } & \text { past tense } \\ \text { CONTR } & \text { contrastive } & \text { PCTIMP } & \text { punctual imperative } \\ \text { CP } & \text { classificatory particle } & \text { PL } & \text { plural } \\ \text { DET } & \text { determiner } & \text { POSS } & \text { possessive } \\ \text { DIR } & \text { directional marker } & \text { PROX } & \text { proximal } \\ \text { DIST } & \text { distal } & \text { PRS } & \text { present tense } \\ \text { DU } & \text { dual } & \text { RT } & \text { relational tense } \\ \text { DUR } & \text { durative } & \text { S } & \text { subject } \\ \text { DX } & \text { proximal deictic } & \text { SFOC } & \text { sentence focus marker } \\ \text { EMP } & \text { emphatic } & \text { SG } & \text { singular } \\ \text { F } & \text { feminine } & \text { Spec } & \text { specifier } \\ \text { FOC } & \text { focus marker } & \text { SUBJ } & \text { subjunctive } \\ \text { INCL } & \text { inclusive } & \text { TR } & \text { transitive } \\ \text { L } & \text { locational } & & \end{array}$

5. Senft (2001: 539) proposes the term 'ad hoc landmark' for Kilivila.

6. Incidentally, the Northern Aslian speech communities are often described as being characterized by a high degree of idiolectal variation and 'individualistic' use of language (see e.g. Benjamin 1985: 234-235, Burenhult 2005a: 6-7).

7. Examples (11) and (12) were collected using the field stimulus kit developed by Seifart (2003).

8. In Solomon Island Pijin, and English as used in the Solomons and elsewhere in the Pacific, the 'bush' refers to the inland area of islands, the jungle area. Note, however, that in Lavukaleve the term feul ( $f e u-l$ 'go inland-LoczR') is not necessarily synonymous with o'as 'bush'. One pair of consultants do use the two terms to refer to the same areas. However, another pair make a distinction between the 'bush' (o'as), which is in this case west, and 'inland' (feul), in this case north. They both use this distinction consistently. It seems that, strictly speaking, feul refers to the center of the island, while more loosely feul can refer to anywhere in the interior of an island. So in this particular instance, the pair was sitting on the eastern coast of Mane Island. The center of the island does indeed lie north of where the pair was sitting, rather than to the west, while the bush lies both to the north and west.

9. Note that under the definitions employed here, both these descriptions would be called 'orientational'.

10. It should be noted in this context that virtually any cue is available to the orientational strategy, including cues which have not been encountered in the data presented here, such as viewpoint-based 'left' and 'right'. This opens up the possibility that some languages unproblematically classified as Absolute or Relative in conventional frames-of-reference typologies will be found nonetheless to rely heavily on orientational rather than locational information. Yélî Dnye, classified as predominantly Absolute by Levinson (2006), may be a case in point. 


\section{References}

Benjamin, Geoffrey. 1985. In the long term: Three themes in Malayan cultural ecology. Cultural values and human ecology in Southeast Asia, Karl L. Hutterer, Terry A. Rambo \& George Lovelace (eds.), 219-278. Ann Arbor MI: University of Michigan, Center for South and Southeast Asian Studies.

Burenhult, Niclas. 2003. Attention, accessibility, and the addressee: The case of the Jahai demonstrative ton. Pragmatics 13: 363-379.

Burenhult, Niclas. 2005a. A grammar of Jahai. Canberra: Pacific Linguistics.

Burenhult, Niclas. 2005b. Landscape terms and toponyms in Jahai: A field report. Working Papers 51: 17-29. Lund: Department of Linguistics, Lund University.

Burenhult, Niclas. 2006. Body part terms in Jahai. Language Sciences 28: 162-180.

Burenhult, Niclas. Forthcoming a. Distance undone: New light on the Jahai multi-term demonstrative system. Demonstratives in cross-linguistic perspective. Michael Dunn, Sérgio Meira and David P. Wilkins (eds.).

Burenhult, Niclas. Forthcoming b. Spatial coordinate systems in demonstrative meaning.

Burenhult, Niclas \& Angela Terrill. In preparation. Orientation and frames of reference typology.

CARG (Cognitive Anthropology Research Group). 1992. Space stimuli kit 1.2. Nijmegen: Max Planck Institute for Psycholinguistics.

Danziger, Eve. 1994. Out of sight, out of mind: Person, perception, and function in Mopan Maya spatial deixis. Linguistics 32: 885-907.

Danziger, Eve. 1996. Parts and their counterparts: Spatial and social relationships in Mopan Maya. Journal of the Royal Anthropological Institute 2(1): 67-82.

Danziger, Eve. 1997. La variation inter-langues dans l'encodage sémantique et cognitif des relations spatiales: Quelques réflexions sur les données Du maya mopan. Diversité des langues et représentations cognitives, Catherine Fuchs and Stéphane Robert (eds.), 58-80. Paris: Ophrys.

Danziger, Eve. 1999. Language space and sociolect: Cognitive correlates of gendered speech in Mopan Maya. Language diversity and cognitive representations, Catherine Fuchs and Stéphane Robert (eds.), 85-106. Amsterdam: John Benjamins.

Danziger, Eve. 2004. Deixis, gesture and spatial frame of reference. Paper presented at the 2003 meeting of the Chicago Linguistic Society.

Fortescue, Michael. 1988. Eskimo orientation systems. Meddelelser om Grønland: Man \& Society 11: 3-30.

Haviland, John B. 1998. Guugu Yimithirr cardinal directions. Ethos 26(1): 7-24.

Hill, Deborah. 1997. Finding your way in Longgu: Geographical reference in a Solomon Islands language. Referring to space: Studies in Austronesian and Papuan languages, Gunter Senft (ed.), 101-126. Oxford: Clarendon Press.

Levinson, Stephen C. 1996. Frames of reference and Molyneux's question: Cross-linguistic evidence. Language and space, Paul Bloom, Mary Peterson, Lynne Nadel and Merrill F. Garrett (eds.), 109-169. Cambridge MA: The MIT Press.

Levinson, Stephen C. 1997. Language and cognition: The cognitive consequences of spatial description in Guugu Yimithirr. Journal of Linguistic Anthropology 7(1): 98-131.

Levinson, Stephen C. 2003. Space in language and cognition: Explorations in cognitive diversity. Cambridge: CUP. 
Levinson, Stephen C. 2006. The language of space in Yélî Dnye. Grammars of space, Stephen C. Levinson \& David P. Wilkins (eds.), 157-205.

Levinson, Stephen C., Sotaro Kita, Daniel B.M. Haun \& Björn H. Rasch. 2002. Returning the tables: Language affects spatial reasoning. Cognition 84: 155-188.

Levinson, Stephen C. \& David P. Wilkins (eds.). 2006. Grammars of space. Cambridge: CUP.

Li, Peggy \& Lila Gleitman. 2002. Turning the tables: Language and spatial reasoning. Cognition 83: 265-294.

Palmer, Bill. 2002 a. Absolute spatial reference and the grammaticalisation of perceptually salient phenomena. Representing space in Oceania: Culture in language and mind, Giovanni Bennardo (ed.), 107-157. Canberra: Pacific Linguistics.

Palmer, Bill. 2002b. Linguistic frame of reference reconsidered. Paper presented at Conference of the Australian Linguistics Society. Macquarie University.

Pederson, Eric. 2003. How many reference frames? Spatial Cognition III: Routes and navigation, human memory and learning, spatial representation and spatial learning, Christian Freksa, Wilfried Brauer, Christopher Habel \& Karl F. Wender (eds.), 287-304. Berlin: Springer.

Pederson, Eric, Eve Danziger, David P. Wilkins, Stephen C. Levinson, Sotaro Kita and Gunter Senft. 1998. Semantic typology and spatial conceptualization. Language 74: 557-589.

Schultze-Berndt, Eva. 2006. Sketch of a Jaminjung grammar of space. Grammars of space, Stephen C. Levinson \& David P. Wilkins (eds.), 63-114. Cambridge: CUP.

Seifart, Frank. 2003. Encoding shape: Formal means and semantic distinctions. Field research manual, 2003, Nick Enfield (ed.), 57-59. Nijmegen: Max Planck Institute for Psycholinguistics.

Senft, Gunter. 2001. Frames of spatial reference in Kilivila. Studies in Language 25(3): 521-555.

Talmy, Leonard. 1983. How language structures space. In: Spatial orientation: theory, research, and application, Herbert Pick \& Linda Acredolo (eds.), 225-282. Plenum Press.

Terrill, Angela. 2003. A grammar of Lavukaleve. Berlin: Mouton de Gruyter.

van der Sluys, Cornelia M. I. 1999. The Jahai of northern peninsular Malaysia. The Cambridge encyclopaedia of hunter-gatherers, Richard B. Lee \& Richard Daly (eds.), 307-311. Cambridge: CUP.

Wassman, Jürg \& Pierre R. Dasen. 1998. Balinese spatial orientation: Some empirical evidence for moderate linguistic relativity. Journal of the Royal Anthropological Institute (inc. Man) 4: 689-711.

Widlok, Thomas. 1997. Orientation in the wild: The shared cognition of Hai//om Bushpeople. Journal of the Royal Anthropological Institute 3: 317-332.

\section{Authors' addresses}

Angela Terrill

Centre for Language Studies

Radboud University Nijmegen

P.O Box 9103

6500 HD Nijmegen, The Netherlands

aterrill@let.ru.nl
Niclas Burenhult

Language and Cognition Group

Max Planck Institute for Psycholinguistics

P.O. Box 310

6500 AH Nijmegen, The Netherlands

niclas.burenhult@mpi.nl 